\title{
Kopplung von Bilirubinoxidase an Kohlenstoffnanoröhren auf Elektroden
}

\author{
Masterthesis \\ zur Erlangung des akademischen Grades \\ Master of Science "M. Sc." \\ Reg.-Nr. BBM/05/08/SS2007 \\ Technische Fachhochschule Wildau \\ Studiengang Biosystemtechnik / Bioinformatik
}

Fachbereich Ingenieurwesen / Wirtschaftsingenieurwesen

\author{
vorgelegt von: Kirsten Schubert \\ eingereicht am: $\quad$ 13. August 2007 \\ Betreuer: $\quad$ Prof. Dr. F. Lisdat
}




\section{Danksagung}

Ich danke Herrn Prof. Dr. F. Lisdat, unter dessen Leitung die vorliegende Arbeit entstand, für das sehr interessante Thema und die zur Verfügung gestellten Arbeitsmittel und Geräte. Insbesondere bin ich ihm auch für die wertvollen Anregungen und die stete Diskussionsbereitschaft zu Dank verpflichtet.

Außerdem möchte ich Herrn Dr. M. Beissenhirtz wegen der Zusage zum recht kurzfristigen Erstellen des zweiten Gutachtens für die vorliegende Arbeit danken.

Desweiteren gilt Herrn Dr. M. Weigel mein Dank für die kurze, aber sehr hilfreiche Einführung in Bezug auf die präparativen Arbeiten.

Weiterhin möchte ich mich bei Daniel Schäfer und Falco Beutler für die gute Zusammenarbeit im Labor und die Unterstützung, die mir während der Anfertigung meiner Arbeit zuteil wurde, herzlich bedanken.

Nicht zuletzt bin ich Ina Bolz zu großem Dank verpflichtet. Sie hat mich immerfort moralisch unterstützt und war mir durch das kritische Korrekturlesen meiner Arbeit vor allem in der Endphase eine sehr große Hilfe. 


\section{Abstract}

In der vorliegenden Arbeit wurde ein Elektrodensystem aus MWCNT-modifizierten Goldelektroden mit kovalent fixierter Bilirubinoxidase elektrochemisch untersucht. Unter aeroben Bedingungen konnte ein DET von der Elektrode zur BOD durch die bioelektrokatalytische Reduktion von Sauerstoff zu Wasser detektiert werden. Das Startpotential der Elektrodenreaktion unter aeroben Bedingungen wurde mit etwa $720 \pm 10 \mathrm{mV}$ gegen SHE ermittelt. Mit dem hier beschriebenen Elektrodensystem sind in luftgesättigtem Puffer (bei $25 \pm 5^{\circ} \mathrm{C}$ ) Stromdichten im Bereich von etwa $500 \mu \mathrm{A} / \mathrm{cm}^{2}$ möglich. Durch Ultraschallbehandlung der Kohlenstoffnanoröhren vor der Präparation, Variation der Auftragungsmenge und der BOD-Konzentration während der Immobilisierung konnte eine Erhöhung des voltammetrischen Meßsignals erzielt werden. Weiterhin war dieses Elektrodensystem bei physiologischem pH-Wert und relativ hoher Ionenstärke einsetzbar und erwies sich im Vergleich zu anderen Proteinelektroden mit bis zu 2 Monaten als sehr lagerstabil.

Unter anaeroben Bedingungen wurde ein Kupferzentrum der Bilirubinoxidase einer direkten Redoxumwandlung unterworfen. Der Nachweis dieses Redoxprozesses gelang erstmalig mit kovalent fixierter Bilirubinoxidase. Bei pH 7 in $100 \mathrm{mM}$ CiP-Puffer mit $25 \mathrm{mV} / \mathrm{s}$ wurde ein formales Potential von etwa $680 \pm 10 \mathrm{mV}$ gegen SHE bestimmt. Dieses Potential entspricht in etwa den in den letzten Jahren publizierten Standardpotentialen für das T1-Kupferzentrum von BOD.[1] Weitere Experimente mit Bilirubin und den Inhibitoren $\mathrm{NaF}$ und $\mathrm{NaN}_{3}$ unter aeroben und anaeroben Bedingungen deuteten ebenfalls daraufhin, daßs beim DET mit BOD die Elektronen von der Elektrode auf das T1Zentrum übertragen werden. 


\section{Inhaltsverzeichnis}

1 Einleitung 1

1.1 Motivation . . . . . . . . . . . . . . . . . . 1

1.2 Aufgabenstellung . . . . . . . . . . . . . . 2

2 Theoretische Grundlagen 3

2.1 Kohlenstoffnanoröhren . . . . . . . . . . . . . . . . . 3

2.1.1 Aufbau und physikalische Eigenschaften . . . . . . . . . . . 3

2.1 .2 Defektstrukturen und Modifizierungen $\ldots \ldots \ldots \ldots \ldots$. . . . . 5

$2.1 .3 \quad$ Elektrokatalytische Eigenschaften $\ldots \ldots \ldots \ldots \ldots \ldots$

$2.1 .4 \quad$ Herstellung von Kohlenstoffnanoröhren . . . . . . . . . . . . . 9

2.2 Bilirubinoxidase . . . . . . . . . . . . . . . . . 10

2.2 .1 Strukturelle Eigenschaften von BOD . . . . . . . . . . . 10

2.2 .2 Elektrochemische Untersuchungen von BOD . . . . . . . . . 13

3 Material und Methoden 17

3.1 Chemikalien . . . . . . . . . . . . . . . . . . . . . . . 17

3.2 Geräte und sonstige Materialien . . . . . . . . . . . . . . . . . 18

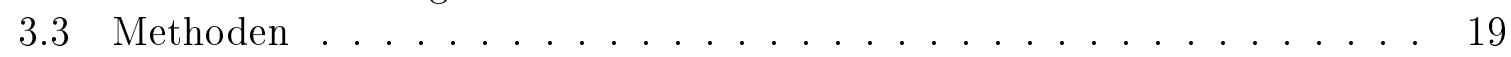

$3.3 .1 \quad$ Elektrodenpräparation . . . . . . . . . . . . . . . . . . . . 19

3.3 .2 Voltammetrische Messungen . . . . . . . . . . . . . . . . 20

3.3 .3 Anaerobe Messungen . . . . . . . . . . . . . . . . . 20

$\begin{array}{lll}4 & \text { Ergebnisse und Diskussion } & 21\end{array}$

4.1 Das Elektrodensystem . . . . . . . . . . . . . . . . . . . 21

4.2 Einfluß der Präparationsbedingungen . . . . . . . . . . . . . . . 24

$4.2 .1 \quad$ Ultraschallbehandlung der Kohlenstoffnanoröhren . . . . . . . . 24

4.2 .2 Auftragungsmenge der Kohlenstoffnanoröhren . . . . . . . . . . 27

$4.2 .3 \quad$ Enzymkonzentration während der Immobilisierung. . . . . . . . . 30

4.3 Charakterisierung der Meßsbedingungen $\ldots \ldots \ldots \ldots \ldots$

4.3 .1 Einfluß des pH-Wertes $\ldots \ldots \ldots \ldots \ldots$

4.3 .2 Einfluß der Ionenstärke des Meßpuffers . . . . . . . . . . . . . 32

4.3 .3 Lagerstabilität $\ldots \ldots \ldots \ldots \ldots \ldots \ldots \ldots$

4.4 Charakterisierung der analytischen Eigenschaften . . . . . . . . . . . 38

4.4 .1 Sauerstoffkonzentration $\ldots \ldots \ldots \ldots \ldots$

$4.4 .2 \quad$ Wechselwirkung mit Bilirubin . . . . . . . . . . . . . . . 39

$4.4 .3 \quad$ Wechselwirkung mit Inhibitoren . . . . . . . . . . . . . . . 41

4.5 Elektrochemisches Verhalten unter anaeroben Bedingungen . . . . . . . . 44 
4.5.1 Direkte Redoxreaktion eines Kupferzentrums . . . . . . . . . . . . 44

4.5 .2 Zugabe von Sauerstoff in geringen Mengen . . . . . . . . . . . . . 48

$4.5 .3 \quad$ Wechselwirkung mit Bilirubin . . . . . . . . . . . . . . 49

4.5 .4 Wechselwirkung mit Inhibitoren . . . . . . . . . . . . . . 50

Zusammenfassung

Literaturverzeichnis $\quad 56$ 


\title{
Abkürzungsverzeichnis
}

\author{
ABTS ........ 2,2-Azino-bis-3-ethylthiazolin-6-sulfonsäure \\ Ar ............ Argon \\ BOD $\ldots \ldots \ldots \ldots$ Bilirubinoxidase \\ BSA ........... bovine serum albumin \\ CiP .......... McIlvain/Whiting's Citrat-Phosphatpuffer \\ CNT ........... carbon nanotube \\ $\mathrm{CV} \ldots \ldots \ldots \ldots$ cyclic voltammetry oder cyclic voltammogram \\ Cys ............. Cystein \\ deion. ......... deionisiert \\ DET ......... direkter Elektronentransfer \\ EDC .......... 1-Ethyl-3-(3-dimethylaminopropyl)-carbodiimid \\ EtOH ......... Ethanol \\ GCE .......... glassy carbon electrode \\ HET ......... heterogener Elektronentransfer \\ His .......... Histidin \\ HOPGE ....... highly oriented pyrolytic graphite electrode \\ IET .......... interner Elektronentransfer \\ kDa $\ldots . . . . . .$. Kilodalton \\ $\mathrm{KHCF} \ldots \ldots$. Kaliumhexacyanoferrat, $\mathrm{K}_{3} / \mathrm{K}_{4}\left[\mathrm{Fe}(\mathrm{CN})_{6}\right]$ \\ LSV ........... linear sweep voltammetry oder linear sweep voltammogram \\ MET ......... mediated electron transfer \\ MWCNT ....... multi-walled carbon nanotube \\ MWCO ....... molecular weight cut off \\ $\mathrm{NaF} \ldots \ldots \ldots$...... Natriumfluorid \\ $\mathrm{NaN}_{3} \ldots \ldots \ldots$.... Natrimazid \\ NaPP ........ Natrium-Phosphatpuffer \\ NHS $\ldots \ldots \ldots . \quad N$-Hydroxysuccinimid \\ PFCE ......... plastic formed carbon electrode \\ PME .......... permselective electrode \\ SHE .......... Standardwasserstoffelektrode \\ SPGE ......... spectroscopic grahpite electrode \\ Sulfo-GMBS .... Sulfo- $N$-succinimidyl-4-maleimidobutyrat \\ SWCNT ....... single-walled carbon nanotubes
}




\section{Einleitung}

\subsection{Motivation}

In der heutigen Zeit ist die Diskussion um den Klimawandel eines der wichtigsten Themen weltweit. Politik und Wirtschaft haben in den letzten Jahren zunehmend in die Nutzung alternativer Energien investiert. Dazu gehört auch die Erforschung neuer alternativer Energien. Sonnenenergie, Erdwärme, Wind- und Wasserkraft sind alltägliche Begriffe. Die Nutzung biologischer Prozesse steckt hingegen noch in den Kinderschuhen. Die Erforschung von sogenannten Bioenergiezellen ist hierfür sehr vielversprechend. Seit den 1960er Jahren sind eine Reihe solcher Energiezellen mit verschiedenen Prinzipien entstanden.[2]

Grundsätzlich soll durch den Verbrauch von "Biokraftstoffen" elektrische Energie generiert werden. Dazu wird ein Anoden- und ein Kathodenraum geschaffen, zwischen denen dann eine Spannungsdifferenz entsteht und somit ein elektrischer Stromfluß. Verschiedene Methoden werden dafür verwendet: direkte Oxidation und Reduktion von organischen Substanzen an der jeweiligen Elektrode, die Verarbeitung solcher Substanzen durch Mikroorganismen, welche dann Elektronen mit den Elektroden direkt oder über Mediatoren austauschen oder enzymkatalysierte Prozesse.[2] Für enzymkatalysierte Prozesse werden Enzyme eingesetzt, die im Anodenraum eine Oxidation und im Kathodenraum eine Reduktion von spezifischen Substanzen wie bspw. Glukose katalysieren. Die treibende Kraft für einen Stromfluß zwischen Anode und Kathode ist eine ausreichend hohe Potentialdifferenz zwischen diesen beiden Elektroden. Demnach müssen Enzyme gewählt werden, die Brennstoffe anodenseitig bei niedrigem Potential oxidieren und Elektronenakzeptoren kathodenseitig bei hohem Potential reduzieren. Weiterhin muß zwischen Enzym und 
Elektrode ein guter Elektronentransfer gewährleistet sein. Dazu ist eine meist orientierte Immobilisierung notwendig, die zudem die biokatalytische Aktivität des Enzyms erhält. Außerdem sind eine sehr gute chemische, thermische und mechanische Stabilität Grundvoraussetzungen für eine industrielle Verwendung.

Bilirubinoxidase katalysiert die Reduktion von Sauerstoff zu Wasser, wobei Elektronen auf den Sauerstoff übertragen werden. Diese Reaktion ist durch ein relativ hohes Reduktionspotential gekennzeichnet, wobei das Enzym auch im neutralen pH-Bereich noch eine hohe Aktivität aufweist.[3] Kohlenstoffnanoröhren besitzen hervorragende Eigenschaften, insbesondere was ihre Leitfähigkeit betrifft. Aufgrund der hohen Oberflächenrauhigkeit, die Schichten aus Kohlenstoffnanoröhren aufweisen, und der vielen verschiedenen Modifikationsmöglichkeiten eignen sie sich ausgezeichnet für die Immobilisierung von Biomolekülen. 4] Somit sind diese Komponenten durchaus für den Einsatz in Bioenergiezellen interessant.

\subsection{Aufgabenstellung}

In dieser Arbeit sollen nun Goldelektroden mit Kohlenstoffnanoröhren modifiziert und daran das Redoxprotein Bilirubinoxidase immobilisiert werden. Anschließend sollen mit diesem Elektrodensystem sowohl Untersuchungen zum elektrochemischen Verhalten des Enzyms, als auch zur Wechselwirkung mit entprechenden Substraten erfolgen. Weiterhin liefern diese Experimente einen Beitrag zur Aufklärung der Elektronentransportprozesse zum und im Enzym. 


\section{Theoretische Grundlagen}

\subsection{Kohlenstoffnanoröhren}

\subsubsection{Aufbau und physikalische Eigenschaften}

Wie der Name schon verrät, sind Kohlenstoffnanoröhren konzentrische Zylinder aus Kohlenstoff in der Größenordnung von Nanometern. Das Verhältnis von Länge zu Durchmesser kann extrem hoch sein. Typische Durchmesser sind 1-50 nm. Nach neueren Forschungsarbeiten können Längen einzelner Röhren bis zu $1 \mathrm{~cm}$ betragen. 5] Dabei bilden CNTs (carbon nanotubes, engl., Kohlenstoffnanoröhren) in der Regel keine starren Gebilde, sondern können auch in der Art kleiner Schläuche flexibel sein. Je nach Umgebungsbedingungen (Lösungsmittel und Modifikationen) neigen sie zur Aggregierung und bilden oft ganze Bündel, die bis zu mehrere Zentimeter lang sein können. 5]

Der strukturelle Aufbau von Kohlenstoffnanoröhren kann am einfachsten mit einem aufgerollten Graphit-Blatt (1 Schicht) beschrieben werden. Eine solch planare Schicht besteht aus hexagonal angeordneten Kohlenstoffatomen, wobei jeweils ein C-Atom drei weitere über $s p^{2}$-Hybridisierung bindet. Generell werden Kohlenstoffnanoröhren in zwei große Gruppen unterschieden. Nanoröhren, die aus einer einzigen Kohlenstoffschicht aufgebaut sind, werden single-walled carbon nanotubes (SWCNTs, engl., einwandige Kohlenstoffnanoröhren) genannt. Es gibt jedoch auch "ineinandergesteckte" Nanoröhren, also mit mehreren zylindrischen Schichten. Diese werden als multi-walled carbon nanotubes (MWCNTs, engl., mehrwandige Kohlenstoffnanoröhren) bezeichnet. Der Abstand zwischen den inneren Röhren beträgt 3,45 А.[6, 7]

Die Geometrie von CNTs wird mit dem Durchmesser, dem chiralen Vektor $C_{h}$ und dem 

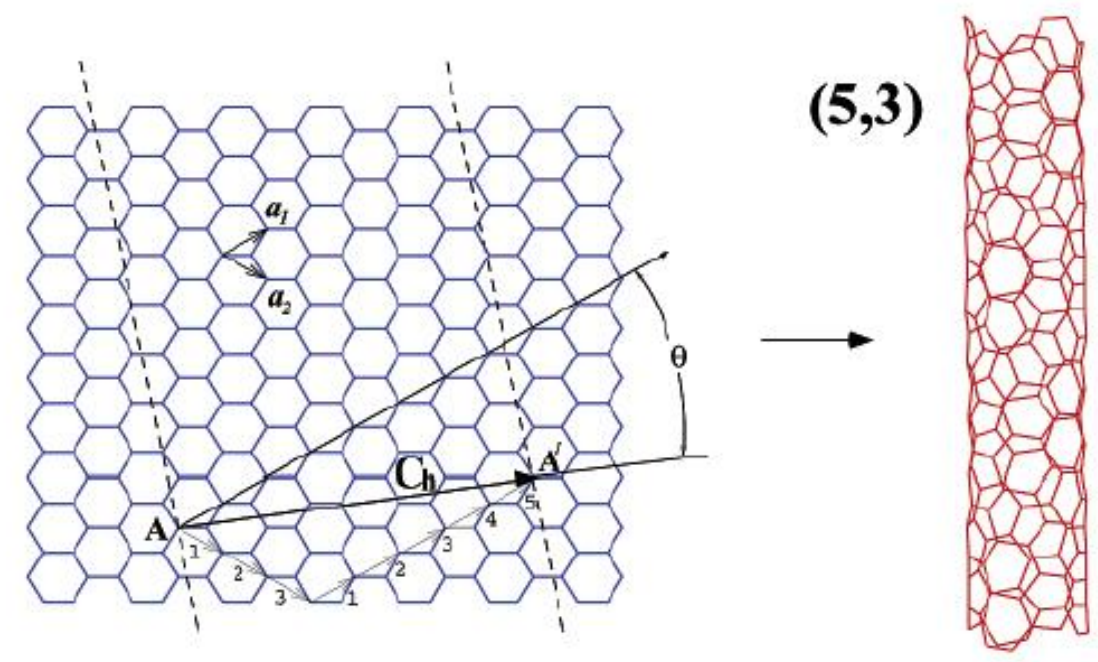

Abbildung 2.1: Schematisiert chiraler Vektor einer Kohlenstoffnanoröhre [7]

chiralen Winkel gekennzeichnet. Der chirale Vektor verbindet zwei kristallographisch äquivalente Punkte auf dem Graphit-Blatt. Beim "Aufrollen” des Blattes zu einer Röhre überdecken sich diese beiden Punkte. Wie in Abbildung 2.1 dargestellt, wird der chirale Vektor durch die Indizes $(n, m)$ beschrieben, die den Bindungen der Kohlenstoffatome zwischen den äquivalenten Punkten (A, A') gemäß der Einheitsvektoren $a_{1}$ und $a_{2}$ folgen:

$$
C_{h}=n a_{1}+m a_{2}
$$

Dabei gibt es zwei Grenzfälle: Ist $n \neq 0$ und $m=0$, dann wird die Röhre als ZigzagTyp bezeichnet; ist $n=m \neq 0$, dann handelt es sich um den Armchair-Typ. Anhand der Geometrie lassen sich Aussagen über die elektronischen Eigenschaften von Kohlenstoffnanoröhren treffen. Grundsätzlich gibt es halb- und metallisch leitende CNTs. Nach theoretischen Berechnungen kann die Leitfähigkeit von idealen CNTs Werte im Bereich von Kupfer bei Raumtemperatur erreichen. Die elektronischen Eigenschaften von Kohlenstoffnanoröhren hängen neben der Häufigkeit von auftretenden Defektstrukturen im wesentlichen von ihrer Geometrie (Durchmesser, Chiralität) ab. Zur Bestimmung des Leitungstyps gibt es folgende Regeln: Armchair-CNTs sind immer metallisch leitend. Ist $n-m$ ein Vielfaches von 3, dann besitzen die Kohlenstoffnanoröhren nur eine sehr kleine Bandlücke zwischen Leitungs- und Valenzband und können bei Raumtemperatur 
praktisch als metallisch leitend eingestuft werden. Ist $n-m$ kein Vielfaches von 3, dann ist die Bandlücke groß und die Kohlenstoffnanoröhren verhalten sich wie Halbleiter. Das trifft ebenfalls auf Zigzag-CNTs zu. Die Krümmung des Kohlenstoffgerüstes ist ebenfalls für eine kleine Bandlücke verantwortlich. Je kleiner der Radius der Röhren ist, desto größer ist die Krümmung und demzufolge auch die Bandlücke. Daher nimmt mit kleiner werdendem Durchmesser auch die Leitfähigkeit in geringem Maße ab. Ausgehend von idealen Kohlenstoffnanoröhren sind die elektronischen Eigenschaften von MWCNTs und SWCNTs sehr ähnlich. Bei MWCNTs tritt zusätzlich eine schwache Kopplung der Leitungsbänder zwischen den einzelnen Zylindern in der Röhre auf. Bei häufigerem Vorkommen von Defektstrukturen in den Kohlenstoffnanoröhren können sich diese Strukturen positiv auf die Gesamtleitfähigkeit auswirken. [6]

Kohlenstoffnanoröhren besitzen auch hervorragende mechanische und thermische Eigenschaften. So ist z.B. das Verhätnis von Zugfestigkeit zu Dichte bei CNTs 135 mal besser als bei Stahl. Die Wärmeleitfähigkeit ist bei Raumtemperatur fast doppelt so hoch wie die von Diamant. Da diese Eigenschaften jedoch keine größere Bedeutung für diese Arbeiten haben, wird an dieser Stelle auch nicht näher darauf eingegangen. [8]

\subsubsection{Defektstrukturen und Modifizierungen}

Perfekte Kohlenstoffnanoröhren besitzen statt offener Enden halbkugelförmige Kappen. Die Krümmung wird dabei durch die pentagonale Anordnung der C-Atome erreicht. Praktisch gesehen entstehen fast keine idealen Kohlenstoffnanoröhren. Es gibt eine Reihe von Defektstrukturen, die bei der Herstellung als auch bei nachträglichen Modifikationen auftreten können. Durch oxidative Prozesse entstehen an den Kohlenstoffnanoröhren meist offene Enden mit abschließenden Carboxylgruppen. Als terminale Gruppen an den Röhrenenden oder auch an Löchern in der Seitenwand können aber bspw. auch Wasserstoff, Sauerstoff, Nitro- oder Hydroxygruppen auftreten.[4] Stehen sich in der Röhrenwand pentagonale und heptagonale Kohlenstoffringe gegenüber, bildet sich ein Knick. Über fünf- und siebengliedrige Ringe können Röhren unterschiedlicher Chiralität auch miteinander verknüpft sein.[7] Einerseits können sich solche Defektstrukturen ungünstig auf die Eigenschaften von Kohlenstoffnanoröhren auswirken. Andererseits ermöglichen 

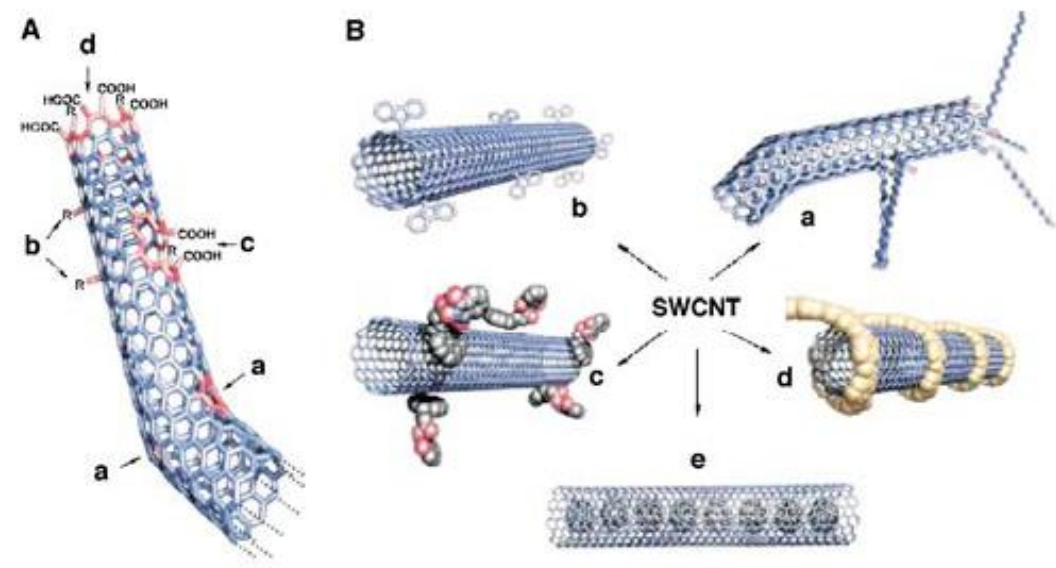

Abbildung 2.2: (A) Typische Defektstrukturen a) penta-und heptagonale C-Ringe b) $s p^{3}$ hybridisierte Gruppen c) Löcher in Seitenwand mit COOH-Gruppen d) offene Enden mit COOH-Gruppen; (B) Mögliche Funktionalisierung a) Kopplung von Molekülgruppen an Defektstrukturen b) kovalente Seitenwandfunktionalisierung c) nichtkovalente exohedrale Funktionalisierung mit Tensiden d) nichtkovalente exohedrale Funktionalisierung mit Polymeren e) endohedrale Funktionalisierung, hier $\mathrm{C}_{60}[4]$

sie teilweise die Modifikation von CNTs. So können z.B. gezielt Thiol-, Amino- oder Carboxylgruppen an der Oberfläche erzeugt werden. Neben der kovalenten Anbindung von Molekülgruppen, sind die CNTs an der Außenwand z.B. mit Kohlenhydraten oder Polymeren nichtkovalent funktionalisierbar. Außerdem sind auch die Röhreninnenräume mit kleinen organischen Molekülen befüllbar. 4] Um die elektrischen Eigenschaften zu beeinflussen, können CNTs auch mit Bor- oder Stickstoffatomen dotiert werden. [6]

Diese vielfältigen Modifizierungen bieten eine ganze Reihe von Möglichkeiten zur Interaktion mit Biomolekülen wie Proteinen. Durch funktionelle Gruppen wie -SH und -COOH sind bewährte Kopplungsstrategien verwendbar. Z.B. können Carboxylgruppen auf den Kohlenstoffnanoröhren mithilfe von Carbodiimiden (bspw. EDC) zur Bindung von Aminogruppen an Proteinen aktiviert werden. Zur Anbindung einer stabileren Aktivierungsgruppe wird meist EDC (1-Ethyl-3-(3-dimethylaminopropyl)-carbodiimid) in Verbindung mit NHS ( $N$-Hydroxysuccinimid) verwendet. Für die Bindung zwischen Thiolgruppen auf CNTs und Aminogruppen an Proteinen kann das Kopplungsreagenz Sulfo-GMBS (Sulfo- $N$-succinimidyl-4-maleimidobutyrat) verwendet werden, das als sogenannter "crosslinker" zwischen den beiden Komponenten verbleibt. Im einfachsten Fall 
lassen sich Proteine an der Kohlenstoffoberfläche aber auch nur gut adsorbieren, ohne daß sie dabei denaturieren. 4

\subsubsection{Elektrokatalytische Eigenschaften}

Bei der ersten elektrochemischen Anwendung von Kohlenstoffnanoröhren von Britto et al. (1996) [9] stellte sich heraus, daß durch die Verwendung einer MWCNT-haltigen Paste als Elektrode eine nahezu ideal reversible Redoxumwandlung von Dopamin erreicht werden konnte. Dopamin unterliegt an anderen Elektrodenmaterialien meist einem irreversiblen Redoxprozeß. Diese Entdeckung führte zur weiteren Untersuchung der elektrokatalytischen Eigenschaft von Kohlenstoffnanoröhren und ihrer elektrochemischen Anwendung.

Bei Kohlenstoffnanoröhren kann im Wesentlichen von 2 entscheidenden Bereichen ausgegangen werden: die Seitenwände und die Enden. Wie in Abschnitt 2.1.1 schon erklärt sind Kohlenstoffnanoröhren nichts anderes als aufgerollte Graphit-Ebenen. In struktureller Hinsicht sind die Wände der Kohlenstoffnanoröhren mit der Oberfläche von basal plane highly oriented pyrolytic graphite-Elektroden (basal plane HOPGE) zu vergleichen (siehe Abb. 2.3). Solche Elektroden sind für einen relativ langsamen Elektronentransfer bekannt. Im Gegensatz dazu weisen edge plane highly pyrolytic graphite-Elektroden (edge plane HOPGE) einen sehr viel schnelleren Elektronentransfer auf. Diese unterschiedlichen elektrochemischen Verhaltensweisen lassen sich auf die kristallographische Richtung der Graphit-Ebenen zur Oberfläche zurückführen. Die Enden von offenen Kohlenstoffnanoröhren entsprechen der Oberfläche von edge plane HOPGEs und haben demnach ein ähnliches elektrochemisches Verhalten. Bei Kohlenstoffnanoröhren mit Kappen an den Enden ist ebenfalls von einer etwas erhöhten Reaktivität gegenüber der Seitenwände auszugehen, da in diesem Bereich die hexagonale Struktur unterbrochen und die Kohlenstoffebene stärker gekrümmt ist. [9, 10]

An verschiedenen Kohlenstoffelektroden hat sich gezeigt, daß die Beschaffenheit der Elektrodenoberfläche ausschlaggebend für den Elektronentransferprozeß ist. Die Erzeugung bestimmter funktioneller Gruppen auf der Oberfläche kann die Elektronentransferrate deutlich steigern. Eine besonders hohe Reakivität weisen Bereiche mit sauerstoffhal- 


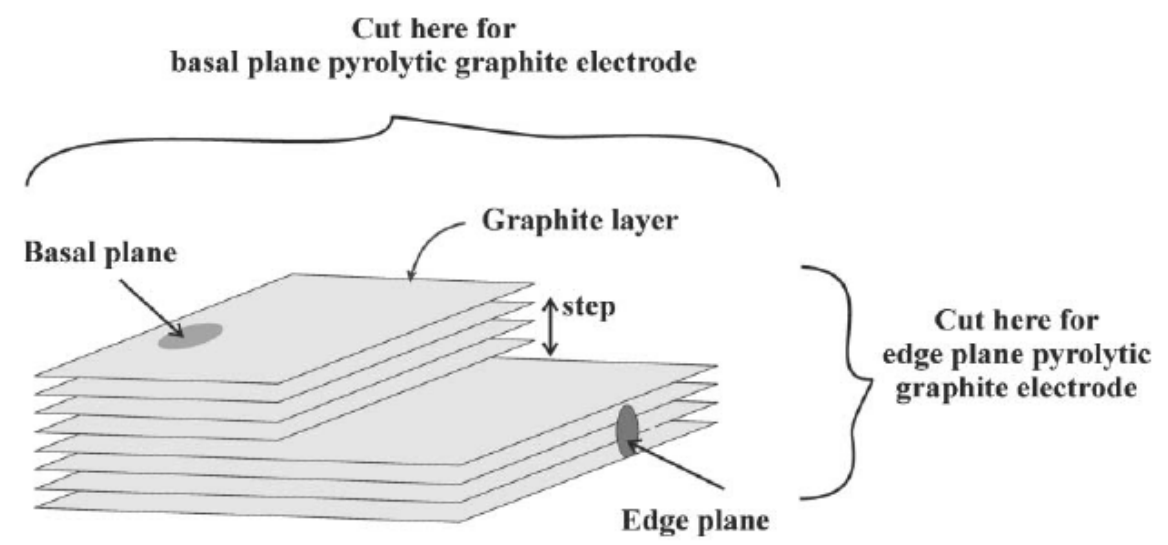

Abbildung 2.3: Schematisierte Graphitebenen bei basal plane oder edge plane highly oriented pyrolytic graphite-Elektroden (HOPGE) [10]

tigen Defektstrukturen wie Carboxyl- und Hydroxygruppen auf. Solche Defekte treten in fast allen Kohlenstoffnanoröhren und besonders an offenen Enden auf. Je mehr solcher Defektstrukturen in den Kohlenstoffnanoröhren vorhanden sind, desto größer ist auch der Bereich, an dem ein schneller Elektronentransfer stattfinden kann. Je nach Herstellungsprozeß und weiterer Behandlung der Kohlenstoffnanoröhren können in ihnen gezielt Defekte erzeugt werden. So ist es bspw. möglich, durch Ultraschallbehandlung die Kohlenstoffnanoröhren zu verkürzen und dabei zusätzliche Defektstellen einzuführen.[11]

Dadurch wird das Verhältnis von edge plane pyrolytic graphite-ähnlichen zu basal plane pyrolytic graphite-ähnlichen Bereichen erhöht, was zur Verbesserung der elektrokatalytischen Eigenschaft der Kohlenstoffnanoröhren führt. Außerdem zeigten Gooding et al. [9] in Experimenten mit Array-artig angeordneten Kohlenstoffnanoröhren auf Elektroden, daß die elektrochemische Reaktion mit Proteinen vorwiegend an den Enden der Kohlenstoffnanoröhren stattfand, trotz dem diese auch an den Seitenwänden adsorbieren konnten. [9, 10]

Einige wenige Arbeitsgruppen beschrieben deutlich detektierbare Redoxpeaks, die auf Oberflächengruppen der Kohlenstoffnanoröhren zurückzuführen waren. Generell kann bei der Verwendung von Kohlenstoffnanoröhren ein hoher Ladestrom beobachtet werden. Brisci et al. [9] zeigten mit SWCNT-Papier als Elektrode, daß sich der kapazitive 
Strom aus dem Ladestrom der Doppelschicht vor der Elektrode und einem "pseudokapazitiven" Strom durch die Redoxreaktion von Oxidgruppen auf der Elektrodenoberfläche zusammensetzte. Die Menge der vorhandenen Oxidgruppen auf den Kohlenstoffnanoröhren beeinflußt demnach auch das Verhalten des Ladestroms. 9]

\subsubsection{Herstellung von Kohlenstoffnanoröhren}

CNTs können mit verschiedenen technischen Methoden hergestellt werden. Dabei handelt es sich um Verdampfungsprozesse, die auf unterschiedlichen Verfahren basieren: z.B. Verdampfen von Kohlenstoff durch Lichtbogenentladung, durch einen Laser oder chemische Zersetzung von Kohlenwasserstoffen. Bei der Lichtbogenentladung (Arc Discharge Deposition) wird in einer Edelgasumgebung (z.B. Helium, Argon) mit Unterdruck zwischen zwei Graphitelektroden, die sich in relativer Nähe zueinander befinden, ein Potential von etwa $25 \mathrm{~V}$ angelegt. Es kommt zur Funkenentladung zwischen den Elektroden, wobei Stromstärken von 60-100 A entstehen. Dabei verdampft das Kohlenstoffmaterial an der Anode und kondensiert als Kohlenstoffnanoröhren und -nanopartikel an der Kathode. Mit diesem Prozeß werden vorwiegend MWCNTs hergestellt. Ist die Anode mit Metallpartikeln (z.B. Kobalt, Nickel) dotiert, können so auch SWCNTs erzeugt werden. Das Kohlenstoffmaterial kann auch mithilfe eines gepulsten oder kontinuierlichen Lasers verdampft werden (Laser Vapourization). Der Prozeß findet in einem Ofen bei $1200^{\circ} \mathrm{C}$ in einer Edelgasumgebung bei Unterdruck statt. Der verdampfte Kohlenstoff bildet bei der Kondensation große Cluster, die Fullerene enthalten. Katalysatoren, die mit verdampft werden, kondensieren langsamer und setzen sich an den Kohlenstoff-Clustern ab, wodurch sie die Schließung der Fullerenstrukturen verhindern oder solche sogar öffnen können. Als Katalysatoren werden Metalle (z.B. Co), Bimetalle (z.B. Fe/Ni) oder bestimmte Oxide (z.B. $\mathrm{La}_{2} \mathrm{O}_{3}$ ) verwendet. Durch Ablagerung weiterer Kohlenstoffatome wachsen aus anfänglichen röhrenförmigen Molekül-Clustern mit Katalysatoren die Kohlenstoffnanoröhren. Die Ausbeute von SWCNTs ist bei diesem Verfahren sehr groß (über 70 \%). Eine weitere Möglichkeit ist die chemische Zersetzung von Kohlenstoffverbindungen wie Methan, Kohlenstoffmonoxid oder Acetylen in der Gasphase (Chemical Vapour Deposition). Zum Aufbrechen der Molekülbindungen wird als Energiequelle entweder 
ein Plasma oder eine Heizspule verwendet. Die Kohlenstoffatome scheiden sich dann auf einem Substrat ab, das mit einem Metallkatalysator beschichtet ist. Die Metallatome bilden Cluster auf der Substratoberfläche. Davon ausgehend erfolgt dann der Wachstumsprozeß der CNTs. Die Wahl des Katalysators hat generell Einfluß auf die Art der Kohlenstoffnanoröhren, Struktur, Durchmesser und Wachstumsrate und ist somit bei allen Verfahren ein wesentlicher Prozeßparameter. [6]

\subsection{Bilirubinoxidase}

\subsubsection{Strukturelle Eigenschaften von BOD}

Für diese Arbeit wurde Bilirubinoxidase (BOD) aus Myrothecium verrucaria verwendet. Bei Myrrothecium verrucaria handelt es sich um eine Schimmelpilzart. Bilirubinoxidase kommt jedoch auch in anderen Organismen vor, wie z.B. verschiedene Prokaryoten und Säugetiere. Das Enzym ist ein Monomer und hat eine globuläre Struktur mit einer Masse von ca. 60 kDa.[12] Die Sequenz aus 534 Aminosäuren mit 2 N-gebundenen Glykosylierungen ist bekannt und in der SwissProt-Datenbank erhältlich. In der Literatur werden auch $O$-gebundene Glykosylierungen erwähnt, deren Position aber noch nicht bestimmt wurde.[13] Bilirubinoxidase gehört zu der speziellen Gruppe von "Blauen" Multikupfer-Oxidasen, die durch bestimmte lichtspektroskopische und elektromagnetische Eigenschaften ihrer 3 Kupferzentren charakterisiert sind. BOD besitzt zwei katalytische Domänen, in die diese 3 Kupferzentren mit 4 Kupferionen integriert sind. Es gibt zwei natürliche Substrate für BOD: Bilirubin und Sauerstoff. Eine der katalytischen Domänen ist durch ein T1-Kupferzentrum mit $1 \mathrm{Cu}$-Ion charakterisiert und für die Oxidation von Bilirubin zu Biliverdin verantwortlich. Die andere katalytische Domäne enthält ein T2-Kupferzentrum mit $1 \mathrm{Cu}$-Ion und ein T3-Kupferzentrum mit $2 \mathrm{Cu}$-Ionen. Das T2- und T3-Zentrum bilden dabei einen trinuklearen Cluster und binden molekularen Sauerstoff während seiner Reduktion zu Wasser in verschiedenen Übergangszuständen. Zur Aufklärung von Struktur und Funktionsweise von Bilirubinoxidase werden vor allem die schon besser untersuchten Laccasen als Modell verwendet.[14] 
Bei der Oxidation von Bilirubin wird ein Elektron vom T1-Zentrum aufgenommen und über einen internen Transferweg auf den T2/T3-Cluster übertragen. Das T1-Zentrum und der trinukleare Cluster sind über die Aminosäurensequenz His-Cys-His mit einem Abstand von $13 \AA$ direkt miteinander verbunden. Sauerstoff fungiert als finaler Elektronenakzeptor.[13] Dieser interne Elektronentransport wird durch eine Potentialdifferenz zwischen den Kupferzentren gewährleistet. Mit Hilfe von potentiometrischen Titrationen wurde das Standardpotential für das T1-Zentrum von BOD aus Myrothecium verrucaria bestimmt. Dazu gibt es mehrere, widersprüchliche Publikationen. Xu et al. (1996) ermittelten ein Standardpotential von $490 \mathrm{mV}$ gegen SHE.[3] Shimizu et al. publizierten 2003 [15] ein ähnliches Potential von $470 \mathrm{mV}$ gegen SHE, wohingegen sie 1999 [16] noch $570 \mathrm{mV}$ (gegen SHE, bei pH 7,8) als Redoxpotential für das T1-Kupferzentrum angaben. Hingegen emittelten Tsujimura et al. (2005) gegen 3 verschiedene Redoxmediatoren ein Standardpotential von $660 \mathrm{mV}$ (bei pH 7, gegen SHE) und Christenson et al. (2006) gegen 2 Redoxmediatoren ein Standardpotential von $670 \mathrm{mV}$ (bei pH 7, gegen SHE).[1] Bei voltammetrischen Messungen wurde der Start der bioelektrokatalytischen Sauerstoffreduktion durch BOD bei Potentialen von etwa $700 \mathrm{mV}$ beobachtet. Tsujimura et al. (2004) bestimmten ein Startpotential von $735 \mathrm{mV}$ (bei pH 7, gegen SHE).[17] Kamitaka et al. (2006) publizierten ein Startpotential von $695 \mathrm{mV}$ (bei pH 7, gegen SHE).[18] Diese widersprüchlichen Angaben erschweren die Zuordnung von Meßergebnissen.

Generell können "Blaue" Multikupfer-Oxidasen in Bezug auf ihr T1-Zentrum nochmal in 3 Gruppen unterteilt werden: Enzyme mit niedrigem $(340-490 \mathrm{mV}$ gegen SHE), mittlerem $(470-710 \mathrm{mV}$ gegen SHE) und hohem Potential $(730-780 \mathrm{mV}$ gegen SHE).[3] Aufgrund der widersprüchlichen Potentialwerte ist eine Einteilung von Bilirubinoxidase in eine dieser Gruppen schwierig.

$\mathrm{Zu}$ den Redoxpotentialen von $\mathrm{T} 2$ und $\mathrm{T} 3$ gibt es in der Literatur für BOD bisher fast keine Daten. Einige wenige Untersuchungen wurden jedoch für Laccasen gemacht. Das Redoxpotential von T2 in Laccase aus Rhus vernicifera soll demnach bei $390 \mathrm{mV}$ (gegen SHE) liegen. Die Laccase aus $R$. vernicifera ist ein Enzym mit niedrigem T1Potential, aus T. versicolor eines mit hohem T1-Potential. Für ersteres wurde ein T3Redoxpotential von $450 \mathrm{mV}$, für zweites eines von $785 \mathrm{mV}$ gegen SHE bestimmt.[3] Aus- 


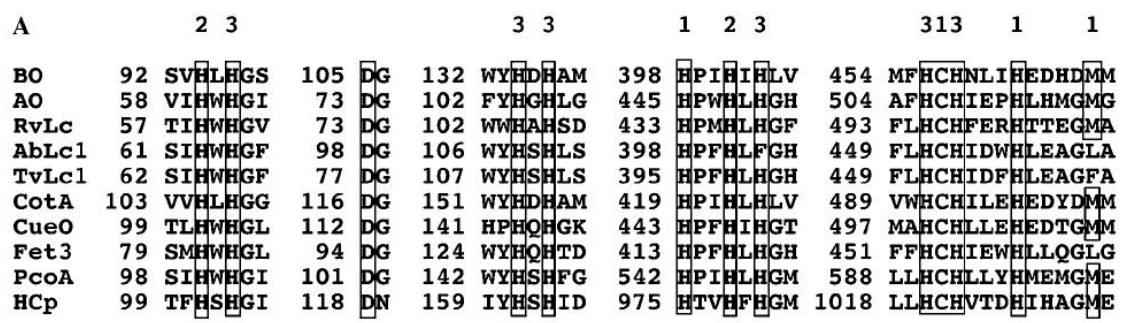

B

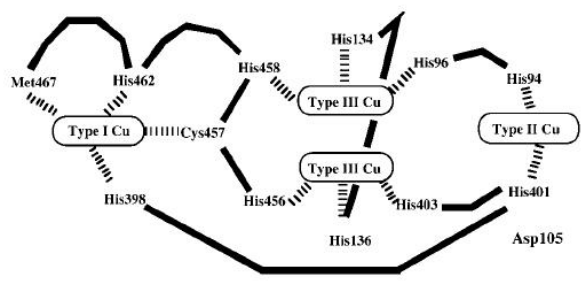

Abbildung 2.4: (A) Homologe Aminosäuresequenzen in Multikupfer-Oxidasen zur Bindung von $\mathrm{Cu}$, (BO) Bilirubinoxidase, (AO) Ascorbat Oxidase, (RvLc) Rhus vernicifera Laccase, (AbLc1) A. thaliana Laccase, (TvLc) Trametes versicolor Laccase, (HCp) menschliches Ceruplasmin; Die Nummern oben kennzeichnen das betreffende $\mathrm{Cu}$-Zentrum; (B) Schematisiert Komplexierung der Kupferzentren in BOD [7]

gehend davon, daß BOD aus $M$. verrucaria und Laccase aus $R$. vernicifera die gleichen Aminosäuren zur Komplexierung der Kupferzentren haben (siehe Abb. 2.4), liegt die Vermutung nahe, daß auch die Redoxpotentiale etwa gleich sind. Demnach wäre für BOD das T1-Potential $490 \mathrm{mV}$ [3], T2 $390 \mathrm{mV}$ und T3 $450 \mathrm{mV}$ (gegen SHE). Diese Potentiale würden jedoch aus thermodynamischen Gesichtspunkten keinen internen Elektronentransfer zulassen. Die Übertragung von Elektronen findet immer von der Redoxspezies mit dem negativeren Standardpotential auf diejenige mit dem positiveren Redoxpotential statt. Dabei ist zwar zu beachten, daß das T2- und T3-Zentrum einen Cluster bilden und das Redoxpotential sich mit der Bindung des Sauerstoffs ändert, fraglich ist dabei jedoch, ob sich das Potential dadurch ausreichend stark erhöht. Zudem widersprechen neuere elektrochemische Untersuchungen [17, 1, 18] diesem Bild, bei denen ein deutlich höheres Potential für T1 bestimmt wurde. 


\subsubsection{Elektrochemische Untersuchungen von BOD}

Bilirubinoxidase wurde schon in verschiedenen Elektrodensystemen für elektrochemische Anwendungen verwendet, darunter auch Bioenergiezellen. Meist basierten diese Systeme auf verschiedenen Kohlenstoffelektroden (GCE, SPGE, HOPGE, PFCE).

Zur Übertragung der Elektronen von der Elektrode auf das Enzym wurden bei den ersten Anwendungen lösliche Mediatoren verwendet (MET). Kamitaka et al. [18] verwendeten z.B. $\mathrm{K}_{3}\left[\mathrm{Fe}(\mathrm{CN})_{6}\right]$ als Mediator, um Elektronen zur BOD zu transportieren.

Bei weiteren Entwicklungen fungierten vorwiegend Redoxpolymere als Mediatorschicht. Bspw. haben Mano et. al [19], Mano und Heller [20], als auch Kim et al. 21] Bioenergiezellen vorgestellt, bei denen der Elektronentransfer kathodenseitig über ein RedoxCopolymer aus Polyacrylamid und Poly $(N$-vinyl-imidazol $)$, komplexiert mit $[$ Os $(4,4$ 'dichloro-2,2'-bipyridin $\left.)_{2} \mathrm{Cl}_{2}\right]^{+/ 2+}$ vermittelt wurde.

Die nächste Stufe dieser Entwicklungen war die Verwendung von Mediatoren auf der Elektrode. Lim et al. [22] publizierten bspw. eine Sol-Gel-Silizium-Matrix mit eingeschlossenen Kohlenstoffnanoröhren auf einer Goldelektrode als Promotorschicht und ABTS (2,2-Azino-bis-3-ethylthiazolin-6-sulfonsäure) als Redoxmediator zur Übertragung der Elektronen auf BOD.

Auch der direkte Elektronentransfer (DET) zwischen Elektrode und Bilirubinoxidase wurde in der Literatur schon beschrieben. Dieser kann anhand des katalytischen Stromes aus der Sauerstoffreduktion beobachtet werden. Auch hier sind bisher vorwiegend Kohlenstoffelektroden eingesetzt worden.

Die Detektion des DET wurde anhand des bioelektrokatalytischen Stromes der Sauerstoffreduktion durch BOD erstmals von Tsujimura et al. [17] beschrieben. Sie verwendeten dabei verschiedene Kohlenstoffelektroden (edge/basal plane HOPGE, PFCE, GCE). Das Startpotential für den katalytischen Strom betrug etwa $735 \mathrm{mV}$ (gegen SHE, bei pH $7 \mathrm{mit} 20 \mathrm{mV} / \mathrm{s}$ ). Tsujimura et al. erreichten eine maximale Stromdichte von $300 \mu \mathrm{A} / \mathrm{cm}^{2}$ bei Verwendung von PFC-Elektroden.

Shleev et al. [3] verwendeten SPG-Elektroden. Sie fanden bei $\mathrm{pH} 4 \mathrm{mit} 10 \mathrm{mV} / \mathrm{s}$ ein Startpotential für die Sauerstoffkatalyse von $800 \mathrm{mV}$ gegen SHE. Ausgehend von einer Verschiebung des Potentials um etwa $30 \mathrm{mV} / \mathrm{pH}$ entspricht das $710 \mathrm{mV}$ bei $\mathrm{pH}$ 7. Die 
Stromdichte betrug etwa $30 \mu \mathrm{A} / \mathrm{cm}^{2}$ (bei $485 \mathrm{mV}$ gegen $\mathrm{SHE}$ ).

Kamitaka et al. [18] publizierten die zyklovoltammetrischen Untersuchungen von BOD mit und ohne Mutation auf HOPG-Elektroden. Bei der mutierten Spezies wurde eine Aminosäure am T1-Kupferzentrum ausgetauscht. Für die unmutierte Spezies fanden sie ein Startpotential von etwa $695 \mathrm{mV}$ (gegen SHE, bei pH 7 mit $20 \mathrm{mV} / \mathrm{s}$ ) für den katalytischen Strom. Bei einem Potential von $485 \mathrm{mV}$ und einer Scanrate von $20 \mathrm{mV} / \mathrm{s}$ lag die gemessene Stromdichte bei etwa $240 \mu \mathrm{A} / \mathrm{cm}^{2}$. Das Startpotential für die mutierte Spezies war mit etwa $465 \mathrm{mV}$ (gegen SHE) deutlich negativer, was für einen Elektronentransfer auf das T1-Kupferzentrum spricht.

Zur Verbesserung der Elektronenübertragung wurden Kohlenstoffelekroden eingesetzt, die mit Kohlenstoffnanoröhren modifiziert waren. Dazu gibt es ebenfalls mehrere Arbeiten. Zheng et al. 23] beschichteten Glaskohlenstoffelektroden mit MWCNTs, die mit Cellulose-Derivaten modifiziert waren. Zheng et al. gaben zwar ein Startpotential für die Sauerstoffreduktion von $490 \mathrm{mV}$ gegen SHE an, die abgebildeten Voltammogramme zeichnen jedoch dieses Potential gegen $\mathrm{Ag} / \mathrm{AgCl}$ aus, was im Bereich der Werte von Kamitaka et al. und Weigel et al. liegt. Bei einem Potential $485 \mathrm{mV}$ (gegen SHE) erreichten Zheng et al. eine Stromdichte von ca. $90 \mu \mathrm{A} / \mathrm{cm}^{2}$ (mit $10 \mathrm{mV} / \mathrm{s}$ ).

Weigel et al. [24] verwendeten ebenfalls Glaskohlenstoffelektroden und modifizierten diese mit MWCNTs. Sie gaben für die Sauerstoffkatalyse bei pH 7 mit $10 \mathrm{mV} / \mathrm{s}$ ein Halbstufenpotential von $585 \mathrm{mV}$ (gegen SHE) und eine Stromdichte von ca. $40 \mu \mathrm{A} / \mathrm{cm}^{2}$ (bei $565 \mathrm{mV}$ gegen SHE) an.

Shleev et al. und Weigel et al. publizierten außerdem die direkte Redoxumwandlung eines der Kupferzentren in Bilirubinoxidase unter anaeroben Bedingungen. Shleev et al. [3] ließen Bilirubinoxidase auf permselective membrane-Elektroden (PME) adsorbieren. Unter anaeroben Bedingungen bei pH 7,4 mit $100 \mathrm{mV} / \mathrm{s}$ konnten sie einen kleinen kathodischen Peak bei $300 \mathrm{mV}$ und einen kleinen anodischen Peak bei $730 \mathrm{mV}$ gegen SHE detektieren. Das formale Potential gaben sie mit $515 \mathrm{mV}$ gegen SHE an. Kritisch zu betrachten ist die hohe Peakseparation von $430 \mathrm{mV}$. Es ist unwahrscheinlich, daß beide Peaks zum gleichen Redoxzentrum gehören. Außerdem sind die Peakpotentiale in dem publizierten Zyklovoltammogramm nicht deutlich zu bestimmen, trotz dem die Meßkur- 


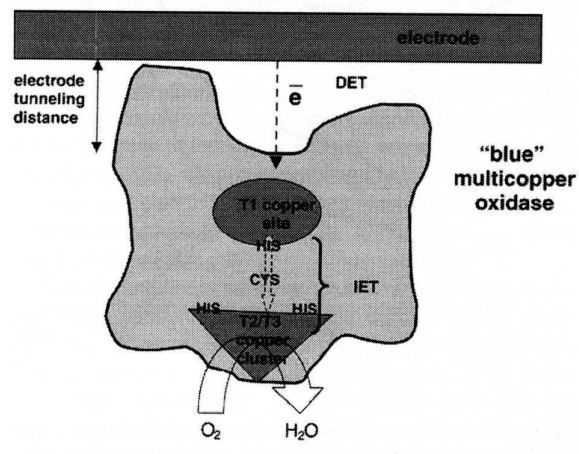

(a)

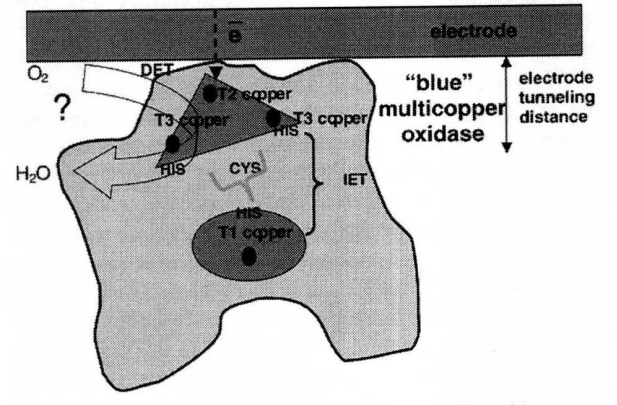

(b)

Abbildung 2.5: Schematisierter möglicher Elektronentransferweg zwischen Elektrode und einigen Multikupfer-Oxidasen, (a) Übertragung auf T1-Zentrum, (b) Übertragung auf T2Zentrum [3]

ve schon um das Hintergrundsignal korrigiert wurde.

Weigel et al. [24] arbeiteten mit MWCNT-modifizierten Glaskohlenstoffelektroden, auf der Bilirubinoxidase in hoher Konzentration mithilfe einer Membran (MWCO $14 \mathrm{kDa}$ ) immobilisiert wurde. Dabei war die BOD auf der Elektrode adsorbiert und befand sich in Lösung unmittelbar vor der Elektrode. Sie detektierten unter anaeroben Bedingungen eindeutig ein Paar Redoxpeaks und konnten diese der Redoxumwandlung eines aktiven Kupferzentrums von BOD zuordnen. Sie bestimmten für dieses Kupferzentrum bei pH $7,4 \mathrm{mit} 25 \mathrm{mV} / \mathrm{s}$ ein formales Potential von $685 \mathrm{mV}$ gegen SHE.

Der Übertragungsweg der Elektronen von der Elektrode auf Multikupfer-Oxidasen ist möglicherweise von der Art bzw. vom Material der Elektrode abhängig. Für Laccasen an Kohlenstoff- und Goldelektroden wurden in der Literatur abweichende Verhaltensweisen beschrieben. Wie in Abbildung 2.5 dargestellt wird dabei an Kohlenstoffelektroden der Transfer von Elektronen auf das T1-Zentrum, an Goldelektroden der Transfer auf das T2-Zentrum vorgeschlagen. [3]

Für den direkten Elektronentransfer zwischen Goldelektroden und Bilirubinoxidase wurden auch erste Arbeiten publiziert. Christenson et al. [1] verwendeten unmodifizierte Goldelektroden für zyklovoltammetrische Messungen und die direkte spektroelektrochemische Redoxtitration von BOD aus Myrothecium verrucaria und Trachyderma tsunodae 
unter anaeroben Bedingungen. Bei den zyklovoltammetrischen Messungen konnten sie keinen faradayischen Strom detektieren. Die direkte Redoxtitration von Bilirubinoxidase an Goldelektroden führte zur Änderung der Absorption bei $600 \mathrm{~nm}$. Oxidation und Reduktion wiesen dabei jedoch einen unterschiedlichen Absorptions-Potential-Verlauf auf, was auf einen komplexeren Mechanismus bei DET gegenüber MET schließen läßt. Fraglich ist aber der Zustand des Enzyms auf der Goldoberfläche. Viele Proteine denaturieren auf Metalloberflächen.

Dronov et al. 25] publizierten erst kürzlich den direkten Elektronentransfer zwischen Goldelektroden und Bilirubinoxidase. Die verwendeten Golddrahtelektroden waren dazu mit einer Promotorschicht aus Mercaptoundecanol und Mercaptoundecansäure modifiziert. Dronov et al. bestimmten für BOD in Lösung bei pH 4 mit $20 \mathrm{mV} / \mathrm{s}$ ein Startpotential für die Sauerstoffreduktion von $585 \mathrm{mV}$ gegen SHE. Die resultierende Stromdichte war jedoch mit wenigen $\mu \mathrm{A} / \mathrm{cm}^{2}$ sehr gering. 


\section{Material und Methoden}

\subsection{Chemikalien}

\begin{tabular}{|c|c|c|}
\hline Substanz & chemische Formel & Bezugsquelle \\
\hline Argon & Ar & Air Liquide Deutschland GmbH, Dtl. \\
\hline Bilirubin & $\mathrm{C}_{33} \mathrm{H}_{36} \mathrm{~N}_{4} \mathrm{O}_{6}$ & Sigma Aldrich Chemie GmbH, Dtl. \\
\hline BOD (EC 1.3.3.5) aus & - & Sigma Aldrich Chemie GmbH, Dtl. \\
\hline \multicolumn{3}{|l|}{ Myrothecium veruccia } \\
\hline BSA & - & Carl Roth GmbH + Co KG, Dtl. \\
\hline Citronensäure & $\mathrm{C}_{6} \mathrm{H}_{8} \mathrm{O}_{7}$ & Merck KGaA, Dtl. \\
\hline di-Natrium- & $\mathrm{Na}_{2} \mathrm{HPO}_{4}$ & Roth GmbH + Co KG, Dtl. \\
\hline \multicolumn{3}{|l|}{ hydrogenphosphat } \\
\hline EDC & $\mathrm{C}_{8} \mathrm{H}_{17} \mathrm{~N}_{3} \cdot \mathrm{HCl}$ & Sigma Aldrich Chemie GmbH, Dtl. \\
\hline $\mathrm{KHCF}(\mathrm{II})$ & $\mathrm{K}_{4}\left[\mathrm{Fe}(\mathrm{CN})_{6}\right]$ & NeoLab Laborbedarf GmbH, Dtl. \\
\hline $\mathrm{KHCF}(\mathrm{III})$ & $\mathrm{K}_{3}\left[\mathrm{Fe}(\mathrm{CN})_{6}\right]$ & Sigma Aldrich Chemie GmbH, Dtl. \\
\hline $\begin{array}{l}\text { MWCNT, kurz und } \\
\text { dünn }\end{array}$ & - & Nanocyl S.A., Belgien \\
\hline Natriumazid & $\mathrm{NaN}_{3}$ & Sigma Aldrich Chemie GmbH, Dtl. \\
\hline Natriumfluorid & $\mathrm{NaF}$ & NeoLab Laborbedarf GmbH, Dtl. \\
\hline NHS & $\mathrm{C}_{4} \mathrm{H}_{5} \mathrm{NO}_{3}$ & Sigma Aldrich Chemie GmbH, Dtl. \\
\hline Sulfo-GMBS & $\mathrm{C}_{12} \mathrm{H}_{12} \mathrm{~N}_{2} \mathrm{O}_{9} \mathrm{~S}$ & Sigma Aldrich Chemie GmbH, Dtl. \\
\hline
\end{tabular}

Tabelle 3.1: Verwendete Substanzen

Als Puffer wurde McIlvain/Whiting's Citrat-Phosphatpuffer (CiP-Puffer) verwendet. 26] 
Zur Herstellung von 100 mM CiP-Puffer, pH 7 wurden 3,560 ml 109 mM Citronensäure mit 16,440 $\mathrm{ml} 251 \mathrm{mM}$ di-Natriumhydrogenphosphat und 25,144 $\mathrm{ml}$ Wasser gemischt. Zur Herstellung anderer pH-Werte wurden die Anteile der Komponenten entsprechend der Vorgaben von McIlvain/Whiting variiert. Der pH-Wert wurde mit einem pH-Meter kontrolliert und gegebenenfalls mithilfe von Natriumhydroxid oder Phosphorsäure eingestellt. Alle Puffer wurden bei $5^{\circ} \mathrm{C}$ aufbewahrt. Bilirubinoxidase (EC 1.3.3.5, BOD) wurde mit einer Reinheit von $20 \%$ und einer spezifischen Aktivität von $31 \mathrm{Units} / \mathrm{mg}$ von Sigma-Aldrich bezogen und ohne weitere Reinigung verwendet. Die gesamte Enzymmenge wurde nach dem Auftauen sofort in $5 \mathrm{mM} \mathrm{CiP-Puffer,} \mathrm{pH} 7$ gelöst, in Mengen zu $30 \mu \mathrm{lmit} 20 \mu \mathrm{M}$ BOD und $5 \mu \mathrm{l}$ mit $500 \mu \mathrm{M}$ aliquotiert und bei $-21^{\circ} \mathrm{C}$ wieder eingefroren.

Die verwendeten MWCNTs hatten einen Reinheitsgrad von $95 \%$ und waren carboxyloder thiolmodifiziert. Die durchschnittliche Länge der Kohlenstoffnanoröhren betrug $1 \mu \mathrm{m}$, der durchschnittliche Durchmesser $10 \mathrm{~nm}$. $10 \mathrm{mg}$ MWCNTs wurden in $1 \mathrm{ml}$ CiPPuffer, pH 7 suspendiert und 15 Minuten mit Ultraschall behandelt, um eine MWCNTStammsuspension herzustellen. Diese wurde bei $5^{\circ} \mathrm{C}$ gelagert. Gebrauchsfertige MWCNTSuspensionen entstanden durch 10fache Verdünnung in Ethanol und weiterer Ultraschallbehandlung für bis zu 16 Stunden. Diese wurden ebenfalls bei $5^{\circ} \mathrm{C}$ gelagert. Sulfo-GMBS wurde unter Argon-Atmosphäre in 25 mM NaPP (Ar-gespült), pH 7,5 gelöst, in Mengen zu $30 \mu \mathrm{l}$ mit $16 \mathrm{mM}$ aliquotiert und bei $-21^{\circ} \mathrm{C}$ eingefroren. Die Argon-Atmosphäre wurde durch ständige Begasung einer offenen Box mit Argongas über einen Trichter erzeugt. Das verwendete Argongas war hochrein (99,9999\%).

Alle Lösungen wurden mit hochreinem Wasser (Ultra Clear Direct UV, Fa. SG Wasseraufbereitung und Regenerierstation GmbH, Dtl.) angesetzt.

\subsection{Geräte und sonstige Materialien}

Für die voltammetrischen Messungen (LSV, CV) wurde ein Potentiostat der Marke Reference 600, Fa. Gamry Instruments, USA verwendet. Als Arbeitselektroden wurden Goldstabelektroden und Glaskohlenstoffelektroden, Fa. Bioanalytical Systems Inc. (BASi), USA verwendet. Die Fläche der Goldstabelektroden betrug 2,01 mm², die der 
GC-Elektroden 7,07 $\mathrm{mm}^{2}$. Hochreiner Platindraht (99,99\%) diente als Gegenelektrode (Eigenbau). Eine $\mathrm{Ag} / \mathrm{AgCl}(1 \mathrm{M} \mathrm{KCl})$-Elektrode diente als Referenzelektrode (Fa. Microelectrodes Inc., USA). Zur Immobilisierung wurde u.a. eine Dialysemembran, Fa. Carl Roth $\mathrm{GmbH}+\mathrm{Co} \mathrm{KG}$ mit einer Ausschlußgrenze von $8 \mathrm{kDa}$ verwendet.

\subsection{Methoden}

\subsubsection{Elektrodenpräparation}

Zur Reinigung und nachfolgenden Modifikation wurden die Elektroden auf SiliziumkarbidSchleifpapier (Matador, Fa. Dieter Schmid Feine Werkzeuge, Dtl.) mit den Korngrößen K800, K1200, K1500, K2000, K2500 und K3000 in angegebener Reihenfolge jeweils 1 Minute naß (deion. Wasser) geschliffen (K3000 2 Minuten) und danach mit deion. Wasser und EtOH abgespült. Anschließend erfolgte die Beschichtung der Elektrodenoberfläche mit thiolmodifizierten Kohlenstoffnanoröhren durch Auftropfen der MWCNTSuspension. Wenn nicht anders angegeben wurden insgesamt $8 \mu \mathrm{g}$ aufgetragen. Die aufzutragende Menge wurde in zwei Teilschritten aufgebracht. Zur gleichmäßigeren Verteilung der Kohlenstoffnanoröhren auf der Oberfläche wurde die Elektrode während des Verdampfungsprozesses des Ethanols langsam gedreht und dabei leicht angeschlagen. Zwischen den beiden Teilschritten wurden die Elektrode und die MWCNT-Suspension einige Minuten $(\max .10 \mathrm{~min})$ im Kühlschrank $\left(5^{\circ} \mathrm{C}\right)$ gelagert. Nach vollständiger Trocknung der modifizierten Elektrodenoberfläche war die Elektrode für Messungen von BOD in Lösung bereit.

Zur kovalenten Anbindung des Enzyms wurden $20 \mu \mathrm{l} 8 \mathrm{mM}$ Sulfo-GMBS aufgebracht und 30 Minuten bei Raumtemperatur $\left(26 \pm 5^{\circ} \mathrm{C}\right)$ inkubiert. Die Sulfo-GMBS-Lösung wurde mit einer Pipette wieder abgenommen. Anschließend wurden $20 \mu \mathrm{l} 10 \mu \mathrm{M}$ BODLösung auf die Elektrodenoberfläche aufgetragen, 1 Stunde bei Raumtemperatur inkubiert und in $5 \mathrm{mM}$ CiP, pH 7 gewaschen. Zur adsorptiven Bindung des Enzyms wurde nicht mit Sulfo-GMBS inkubiert.

Zur Immobilisierung des Proteins mit Hilfe einer Membran wurden auf eine MWCNT- 
modifizierte Elektrode $5 \mu \mathrm{l} 500 \mu \mathrm{M}$ BOD aufgetropft und eine Dialysemembran (MWCO $8 \mathrm{kDa}$ ) mit einem Gummiring über die Elektrode gespannt. Die vollständig präparierte Elektrode wurde meist sofort für Messungen verwendet, sonst jedoch bei $5^{\circ} \mathrm{C}$ in $5 \mathrm{mM}$ CiP, pH 7 gelagert.

\subsubsection{Voltammetrische Messungen}

Die voltammetrischen Experimente wurden in einer elektrochemischen Meßzelle mit 3Elektrodenanordnung durchgeführt. Wenn nicht anders angegeben, beziehen sich alle Potentiale auf die Ag/AgCl-Referenzelektrode. Die Arbeitselektrode war eine modifizierte Gold- oder Glaskohlenstoffelektrode. Das elektrochemische Verhalten der Bilirubinoxidase wurde mithilfe von Zyklovoltammetrie (CV) oder linear sweep voltammetry (LSV) unter aeroben (luftgesättigter Puffer) und anaeroben (Ar-gesättigter Puffer, siehe Abschnitt 3.3.3 Bedingungen untersucht. Dabei war die BOD entweder an die MWCNTmodifizierte Elektrodenoberfläche adsorbiert, kovalent gebunden, hinter einer Dialysemembran immobilisiert oder befand sich in Lösung $(5 \mu \mathrm{M})$. Die Messungen erfolgten in $100 \mathrm{mM}$ CiP, pH 7 bei Raumtemperatur, wenn nicht anders angegeben. Die Scanraten bei LSV und CV betrugen $10 \mathrm{mV} / \mathrm{s}$ oder $25 \mathrm{mV} / \mathrm{s}$, wenn nicht anders angegeben.

\subsubsection{Anaerobe Messungen}

Für Messungen unter sauerstoffarmen Bedingungen wurde der Meßspuffer zuerst mit Hilfe einer Vakuumpumpe entgast und danach mindestens 30 Minuten mit Argon über eine Pipettenspitze gespült. Der Puffer befand sich dabei in einem kleinen Becherglas (10-20 ml). Der Meßpuffer wurde in der Meßzelle mit der präparierten Arbeitselektrode für weitere 60 Minuten gespült. Die Messungen erfolgten dann unter einer ArgonAtmosphäre, die durch ständige Begasung der Lösungsoberfläche in der Meßzelle über eine Pipettenspitze erzeugt wurde. 


\section{Ergebnisse und Diskussion}

\subsection{Das Elektrodensystem}

An dieser Stelle soll zunächst der Aufbau des verwendeten Elektrodensystems vorgestellt werden. Dieses System basiert auf der Arbeit von Weigel et al., bei der das elektrochemische Verhalten von Bilirubinoxidase an blanken und MWCNT-modifizierten Glaskohlenstoffelektroden untersucht wurde.[24] Dieses Konzept wurde zur Verbesserung des heterogenen Elektronentransfers weiterentwickelt.

Das neue Elektrodensystem (siehe Abb. 4.1) bestand aus einer Goldelektrode, die mit Kohlenstoffnanoröhren beschichtet war. Die MWCNT-Schicht wiederum ermöglichte die Immobilisierung von Bilirubinoxidase. Weigel et al. verwendeten carboxyl-modifizierte MWCNTs, die eine direkte kovalente Bindung zwischen Carboxylgruppen der MWCNTs und Aminogruppen des Proteins durch Aktivierung der Carboxylgruppen erlaubten. Im Gegensatz dazu wurden in der vorliegenden Arbeit thiol-modifizierte MWCNTs eingesetzt. Die Thiolgruppen ermöglichten aufgrund von Chemisorption eine wesentlich stabilere Haftung auf der Goldoberfläche der Elektrode. Sie ermöglichten ebenfalls die kovalente Anbindung von Bilirubinoxidase. Dabei wurde das heterogene bifunktionelle Kopplungsreagenz Sulfo-GMBS verwendet, das über eine Maleimidgruppe auf der einen Seite an Thiolgruppen der MWCNTs und auf der anderen Seite durch Spaltung der NHS-Esterbindung an primäre Aminogruppen des Proteins binden kann. Sulfo-GMBS ist ein crosslinker mit der Länge von etwa $10 \AA$.

Mithilfe von LSV wurde unter aeroben und anaeroben Bedingungen der katalytische Strom der Sauerstoffreduktion zu Wasser durch Bilirubinoxidase gemessen. Wie anhand der Abbildung 4.2 zu sehen ist, kann über die katalytische Reaktion der Bilirubinoxi- 


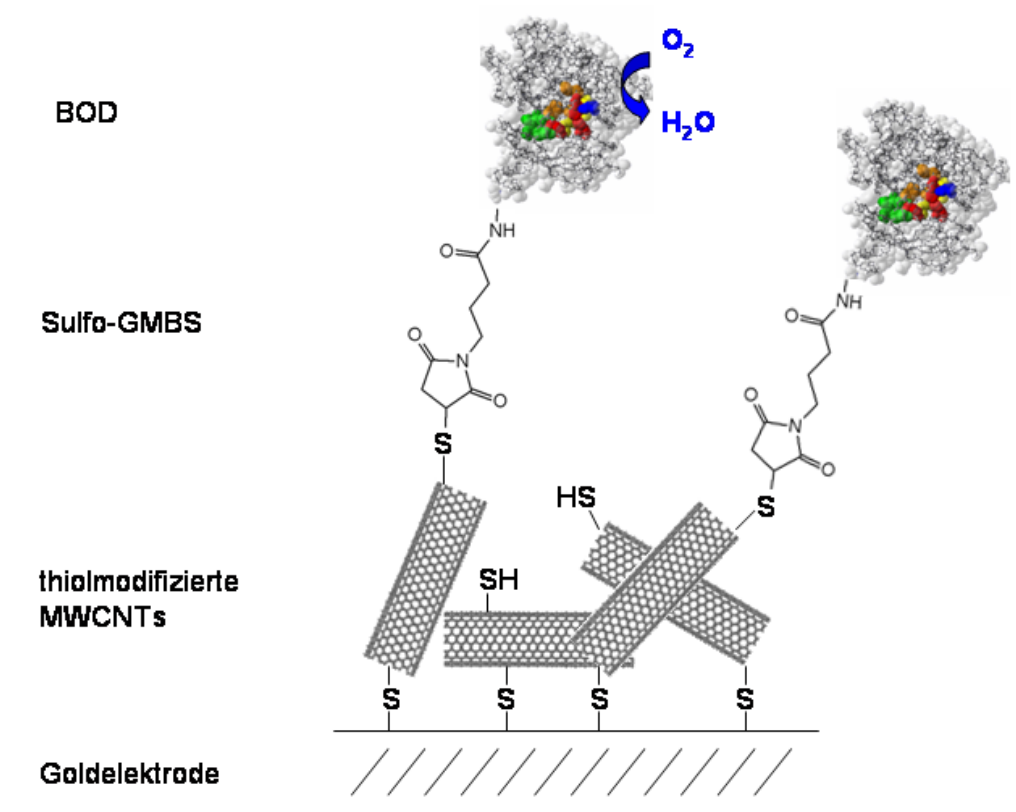

Abbildung 4.1: Schematisierter Aufbau des verwendeten Elektrodensystems

dase an der MWCNT-modifizierten Elektrode eindeutig ein direkter Elektronentransfer beobachtet werden. Zum Vergleich zeigt die Abbildung 4.3 Messungen einer Elektrode ohne immobilisierter BOD. Der katalytische Strom unter aeroben Bedingungen kann demnach auf die katalytische Aktivität der BOD zurückgeführt werden. Die Elektronen werden in einer Art Signalkette von der Goldelektrode über die MWCNTs über die BOD auf den Sauerstoff übertragen. Da die Schicht der Kohlenstoffnanoröhren makroskopisch deutlich sichtbar war, kann aufgrund der Schichtdicke eine direkte Übertragung der Elektronen durch Tunneln zwischen Elektrode und BOD ausgeschlossen werden. Vielmehr belegt diese Messung die sehr gute elektrische Leitfähigkeit der verwendeten Kohlenstoffnanoröhren. Grundsätzlich wurde damit die Funktionsfähigkeit des vorgestellten Elektrodensystems gezeigt, das im Nachfolgenden hinsichtlich der Präparation und der elektrokatalytischen Eigenschaften untersucht wird.

Experimente mit dem Goldelektrodensystem und kovalent gebundener BOD ergaben peak-förmige voltammetrische Meßkurven. Für den katalytischen Strom war eher ein Kurvenverlauf mit flachem Übergang (ohne Peak) in den Gleichgewichstzustand zu er- 


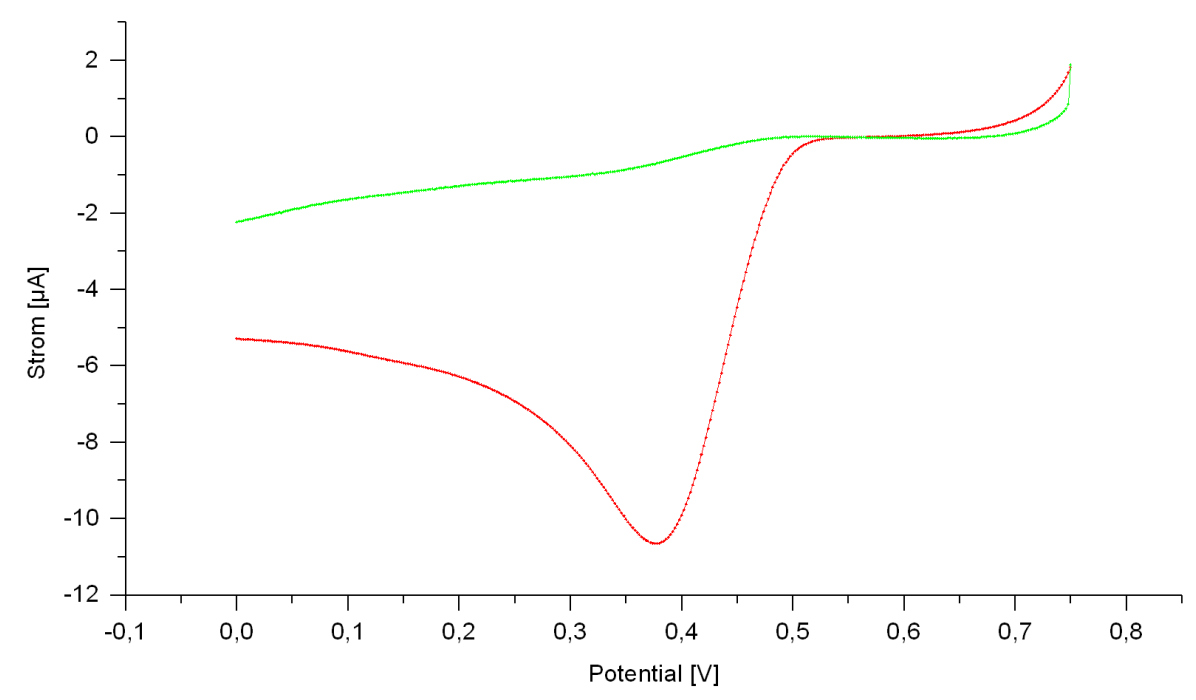

Abbildung 4.2: Nachweis der Funktionsfähigkeit des Elektrodensystems; BOD kovalent gebunden an einer MWCNT-modifizierten Goldelektrode; LSV in (-) luftgesättigtem, (-) Argesättigtem $100 \mathrm{mM} \mathrm{CiP,} \mathrm{pH} \mathrm{7,10mV/s;} \mathrm{Potential} \mathrm{gegen} \mathrm{Ag} / \mathrm{AgCl}$

warten. Wie später noch dargestellt wird, ändert sich bei Belastung der Elektrode durch bspw. viele Messungen und/oder Lagerung über mehrere Tage die Kurvenform, wobei der Peak verschwindet. Wahrscheinlich befindet sich das Enzym in zwei Immobilisierungszuständen auf der Elektrode, kovalent gebunden und adsorbiert, was eine Überlagerung von zwei etwas unterschiedlichen Elektronentransferprozessen zur Folge hat und damit diesen Meßkurvenverlauf verursacht. Eine weitere Erklärung bietet auch die verbesserte Orientierungsmöglichkeit von Bilirubinoxidase durch die kovalente Kopplung an die MWCNT-Schicht über einen crosslinker. Die Peakform läßt auch auf eine besonders hohe katalytische Aktivität der Bilirubinoxidase auf der Elektrode schließen, so daß der Sauerstofftransport in der Lösung limitierend wirkt.

Das Startpotential für die elektrokatalytische Reaktion lag bei $\mathrm{pH} 7$ bei $485 \pm 10 \mathrm{mV}$ gegen $\mathrm{Ag} / \mathrm{AgCl}(720 \mathrm{mV}$ gegen SHE). Dieses Potential liegt etwa in dem Bereich, den auch Tsujimura et al. (735 mV bei pH 7, gegen SHE) [17] und Kamitaka et al. $(695 \mathrm{mV}$ bei pH 7, gegen SHE) [18] für den Beginn der bioelektrokatalytischen Sauerstoffreduktion durch BOD auf Kohlenstoffelektroden angeben. Mit frisch präparierten Elektroden 


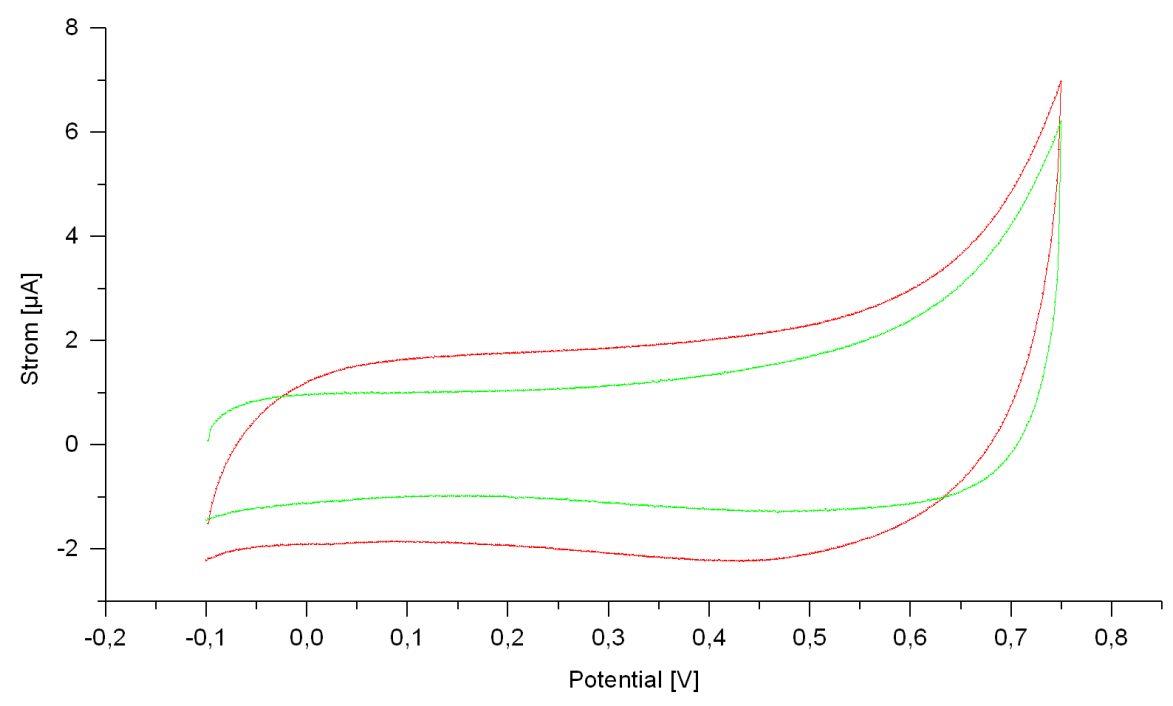

Abbildung 4.3: MWCNTs ohne BOD, CV in luftgesättigtem $100 \mathrm{mM} \mathrm{CiP,} \mathrm{pH} 7,10 \mathrm{mV} / \mathrm{s}$; (-) MWCNT-modifizierte Goledelektrode, (-) MWCNT-Sulfo-GMBS-modifizierte Goldelektrode; Potential gegen $\mathrm{Ag} / \mathrm{AgCl}$

sind mit diesem Elektrodensystem in luftgesättigtem Puffer (bei $25 \pm 5^{\circ} \mathrm{C}$ ) Stromdichten im Bereich von etwa $500 \mu \mathrm{A} / \mathrm{cm}^{2}$ möglich und sind damit deutlich höher als die von Tsujimura et al. $\left(300 \mu \mathrm{A} / \mathrm{cm}^{2}\right)$ [17] und Kamitaka et al. $\left(240 \mu \mathrm{A} / \mathrm{cm}^{2}\right)$ [18] publizierten Werte.

\subsection{Einfluß der Präparationsbedingungen}

\subsubsection{Ultraschallbehandlung der Kohlenstoffnanoröhren}

Aus der Literatur ist bekannt, daß kürzere Kohlenstoffnanoröhren zu höheren Stromsignalen führen.4] CNTs können mithilfe von Ultraschall verkürzt werden. Der Einfluß einer solchen Behandlung auf die Eigenschaften der MWCNTs für die Immobilisierung von Bilirubinoxidase und die Übertragung der Elektronen wurde untersucht.

Messungen mit unterschiedlich lang behandelten MWCNTs führten zu Ergebnissen mit einer hohen Schwankungsbreite. Grundsätzlich ließ sich jedoch durch die Ultra- 


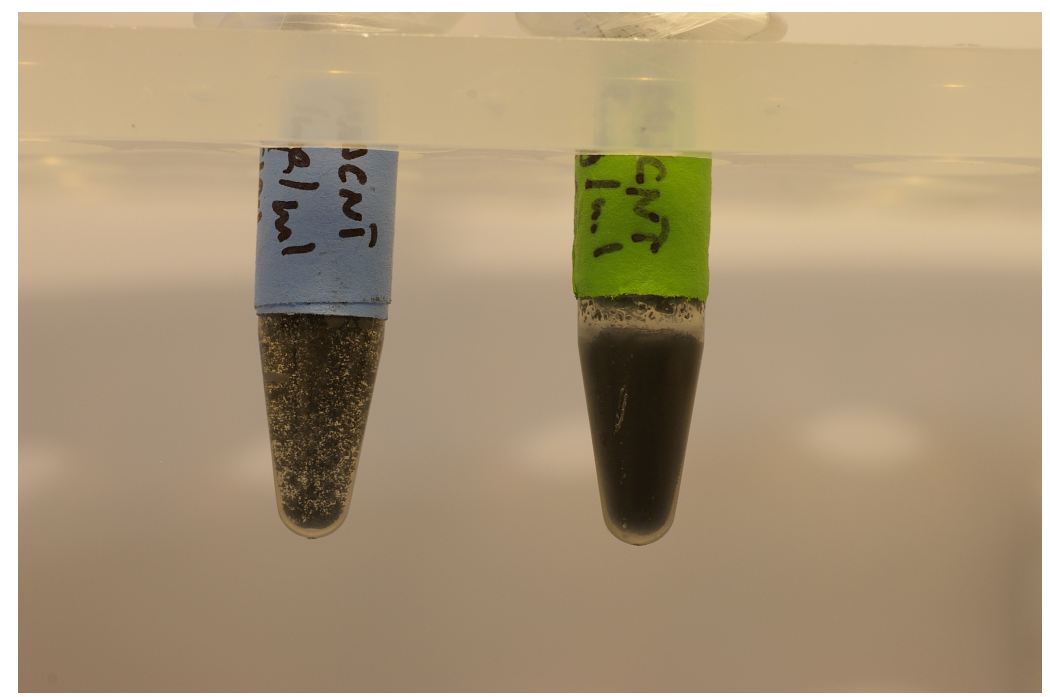

Abbildung 4.4: MWCNT-Suspension $1 \mathrm{mg} / \mathrm{ml}$ in EtOH; links vor Ultraschallbehandlung, rechts nach $16 \mathrm{~h}$ Ultraschallbehandlung

schallbehandlung ein positiver Effekt auf die Eigenschaften der Kohlenstoffnanoröhren in Hinsicht auf die Verwendung als Schichtmaterial auf Elektroden verzeichnen. Die Schwankungsbreite der Meßergebnisse ist möglicherweise auf variierende experimentelle Bedingungen zurückzuführen. Ein wesentlicher Parameter hierbei ist die Temperatur. Das zur Verfügung stehende Ultraschallbad war untemperiert, so daß keine einheitliche Temperatur während der gesamten Ultraschallbehandlung aller Proben gewährleistet werden konnte. Weitergehende Untersuchungen zur genauen zeitlichen Abhängigkeit konnten jedoch im Zeitrahmen dieser Arbeit nicht gemacht werden.

Für die weitere Arbeit wurden MWCNTs verwendet, die $16 \mathrm{~h}$ mit Ultraschall behandelt wurden. Anhand der Abb. 4.4 ist schon deutlich die Veränderung durch die Ultraschallbehandlung zu sehen. Die MWCNT-Konzentration war in beiden Suspensionen gleich. Der Ultraschall verursacht das Brechen bzw. Platzen und möglicherweise auch das teilweise Auseinanderrutschen der verschachtelten Röhren.[11] Dadurch vergrößerte sich bei gleichbleibender Masse die Oberfläche und insbesondere die Anzahl der Defektstellen. Aufgrund der starken Lichtabsorption der Kohlenstoffnanoröhren war dieser Unterschied schon mit bloßem Auge wahrnehmbar.

Goldelektroden wurden zum einen mit Kohlenstoffnanoröhren beschichtet, die nach 


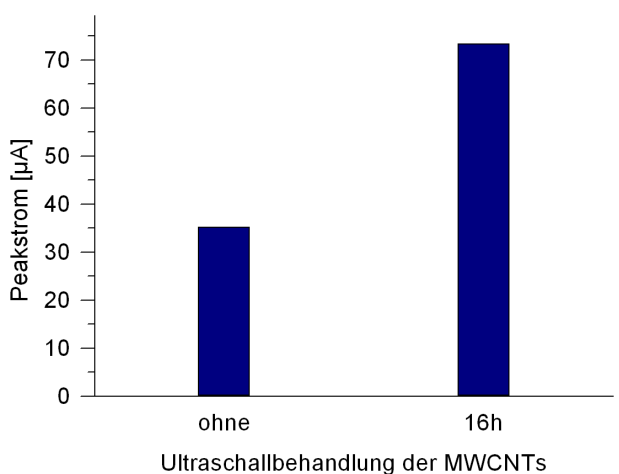

(a)

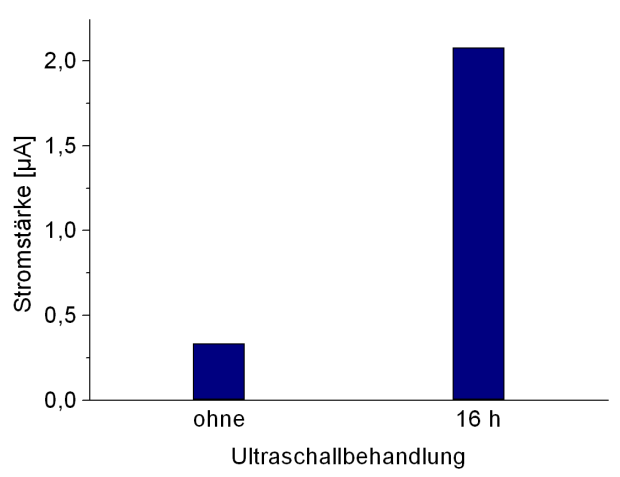

(b)

Abbildung 4.5: Auswirkung der Ultraschallbehandlung der MWCNTs auf das voltammetrische Meßsignal; Stromstärke bei $250 \mathrm{mV}$ (gegen $\mathrm{Ag} / \mathrm{AgCl}$ ); MWCNT-modifizierte Goldelektrode; Messung in (a) $10 \mathrm{mM} \mathrm{KHCF}, 100 \mathrm{mM} \mathrm{CiP,} \mathrm{pH} 7, \mathrm{CV}$ mit $100 \mathrm{mV} / \mathrm{s}$ (b) $5 \mu \mathrm{M}$ BOD (in Lösung), $5 \mathrm{mM} \mathrm{CiP,} \mathrm{pH} \mathrm{7,} \mathrm{LSV} \mathrm{mit} 10 \mathrm{mV} / \mathrm{s}$

der Verdünnung aus der Stammlösung nicht weiter mit Ultraschall behandelt wurden und zum anderen mit welchen, die 16 Stunden dem Ultraschall ausgesetzt waren. Die voltammetrischen Messungen erfolgten sowohl in Puffer mit $10 \mathrm{mM} \mathrm{KHCF}$, als auch in Puffer mit $5 \mu \mathrm{M}$ BOD in Lösung. Die Ergebnisse aus diesen Messungen (siehe Abb. 4.5) zeigen eine signifikante Erhöhung des Stromsignals durch die Verwendung von ultraschallbehandelten Kohlenstoffnanoröhren. Die Meßergebnisse für KHCF (Abb. 4.5a) bestätigen einerseits die Oberflächenvergrößerung. Andererseits werden bei der Ultraschallbehandlung durch oxidative Prozesse zusätzliche Defektstellen an den Kohlenstoffnanoröhren erzeugt. Das sind funktionale Gruppen, mit denen Bilirubinoxidase sehr gut wechselwirken kann. Die vermehrte Anzahl solcher Interaktionsplätze trägt ebenfalls wesentlich zur Verbesserung des katalytischen Stromes bei (Abb. 4.5b).

In der Literatur [4] wurde auch eine mögliche Verbesserung der Leitfähigkeit der Kohlenstoffnanoröhren durch die Ultraschallbehandlung diskutiert. Defektstellen wirken als Widerstand, was an sich die Leitfähigkeit vermindert. Solche Strukturen können aber das Rückstreuen von Elektronen verursachen bzw. können Elektronen diese Stellen auch durch "Überspringen" (electron hopping) überwinden. Dadurch werden die Elektronen 
auf alternative Übertragungswege gelenkt, was in Summe eine Verbesserung des Elektronentransfers verursachen könnte. Theoretische Studien sagen einen solchen Mechanismus voraus. [4]

\subsubsection{Auftragungsmenge der Kohlenstoffnanoröhren}

Um ein möglichst hohes Meßsignal mit dem vorgestellten Elektrodensystem zu erhalten, wurde auch die Auftragungsmenge der Kohlenstoffnanoröhren auf der Goldelektrode variiert. Dazu erfolgten voltammetrische Messungen in $10 \mathrm{mM}$ KHCF und $5 \mu \mathrm{M}$ BOD in Lösung. Ein wichtiges Kriterium bei diesem Experiment ist auch die Art und Weise der CNT-Auftragung. Es wurden 2 Verfahren zur Beschichtung der Goldelektrode mit MWCNTs angewandt. Bei Verfahren I erfolgte die Auftragung ab einer Gesamtmenge von $2 \mu \mathrm{g}$ in 2 Schritten $(2 * \mathrm{n} \mu \mathrm{g})$. Bei einer Auftragungsmenge von mehr als $2 \mu \mathrm{g}$ verteilten sich die CNTs damit auch zunehmend über die eigentliche Goldoberfläche hinaus, so daß die Schicht vertikal, als auch horizontal wuchs.

Sowohl für KHCF, als auch für BOD in Lösung ist deutlich ein Anstieg des Meßsignals mit zunehmender MWCNT-Menge auf der Elektrode zu verzeichnen (Abb. 4.6). Das heißt, die redoxaktive Fläche der Elektrode wurde größer. Besondere Beachtung verdienen die BOD-Meßwerte im unteren Bereich der Auftragungsmenge. Der erste Meßwert für Bilirubinoxidase zeigt, daß ohne die Schicht aus Kohlenstoffnanoröhren nahezu keine meßbare katalytische Aktivität vorhanden war. Das kleine Stromsignal für die unbeschichtete Goldelektrode in der BOD-haltigen Lösung kann hauptsächlich auf den Ladestrom zurückgeführt werden. Kontrollexperimente haben gezeigt, daß Bilirubinoxidase an der blanken Goldoberfläche adsorbiert, aber kein katalytischer Strom detektierbar war, was auf die Denaturierung des Proteins schließen läßt. Damit wird deutlich, daß das Elektrodensystem mit Bilirubinoxidase an einer Goldelektrode ohne die Modifizierung mit Kohlenstoffnanoröhren nicht funktioniert.

Im Bereich von 8-10 $\mu \mathrm{g}$ MWCNTs stieg das Meßsignal nicht weiter an, obwohl immer mehr Material aufgetragen wurde. Durch die immer größer werdende, schichtartige Struktur konnte möglicherweise ein Teil der Elektronen nicht mehr vollständig bzw. stark zeitverzögert zwischen Elektrode und KHCF bzw. BOD transferiert werden. Bi- 


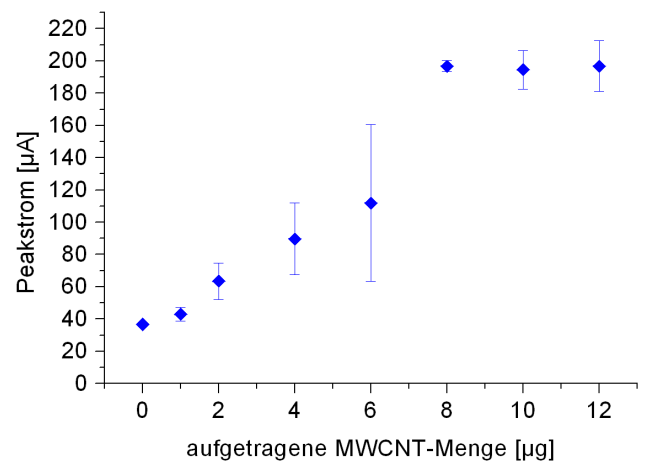

(a)

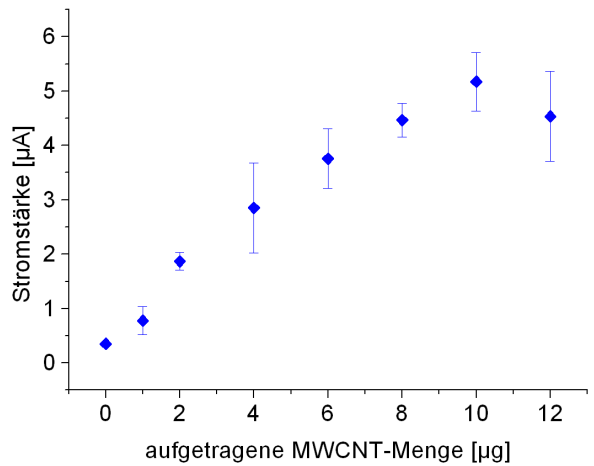

(b)

Abbildung 4.6: Abhängigkeit der Stromdichte von der aufgetragenen MWCNT-Menge mit Verfahren I $(2 * \mathrm{n} \mu \mathrm{g})$; Stromstärke bei $250 \mathrm{mV}$ (gegen $\mathrm{Ag} / \mathrm{AgCl}$ ); MWCNT-modifizierte Goldelektrode; Messung in (a) $10 \mathrm{mM} \mathrm{KHCF}, 100 \mathrm{mM} \mathrm{CiP}, \mathrm{pH} 7 \mathrm{mit} \mathrm{CV}, 100 \mathrm{mV} / \mathrm{s}$, (b) $5 \mu \mathrm{M}$ BOD (in Lösung), $5 \mathrm{mM} \mathrm{CiP,} \mathrm{pH7} \mathrm{mit} \mathrm{LSV,} 10 \mathrm{mV} / \mathrm{s} ;$ Fehlerbalken ergeben sich aus der Messung von 3 Elektrode

lirubinoxidase kann aufgrund seiner Größe nicht weit in die MWCNT-Matrix eindringen und somit nur an Interaktionsstellen an der Oberfläche der Schicht reagieren. KHCF ist ein sehr schnelles Redoxsystem, was dazu führt, daß es ebenfalls nicht in die MWCNTSchicht eindringt, sondern schon in einer Oberflächenschicht nahezu vollständig reagiert.

Um möglichst nur die Schichtdicke der Kohlenstoffnanoröhren, also die vertikale Ausdehnung und nicht die horizontale zu vergrößern, wurde ein II. Verfahren zur Beschichtung angewandt. Dabei erfolgte die Autragung der MWCNT-Gesamtmenge in mehreren Schritten mit je $1 \mu \mathrm{g}(\mathrm{n} * 1 \mu \mathrm{g})$. Bei der Aufbringung von $1 \mu \mathrm{g}$ MWCNT bedeckten diese

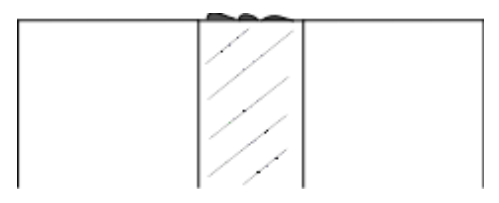

(a)

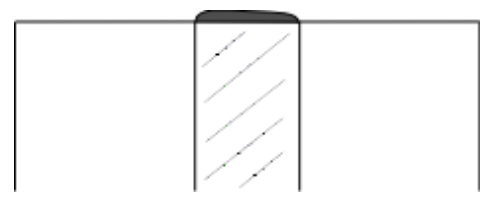

(b)

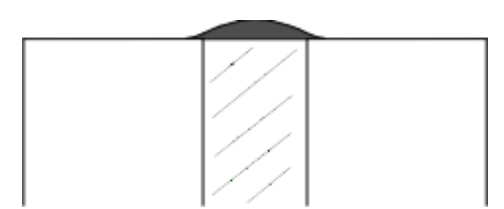

(c)

Abbildung 4.7: Schematisch MWCNT-Beschichtung auf der Elektrode mit Verfahren II ( $\mathrm{n} * 1 \mu \mathrm{g})$; (a) $<2 \mu \mathrm{g}$ MWCNT, (b) $2 \mu \mathrm{g}$ MWCNT, (c) $>2 \mu \mathrm{g}$ MWCNT 


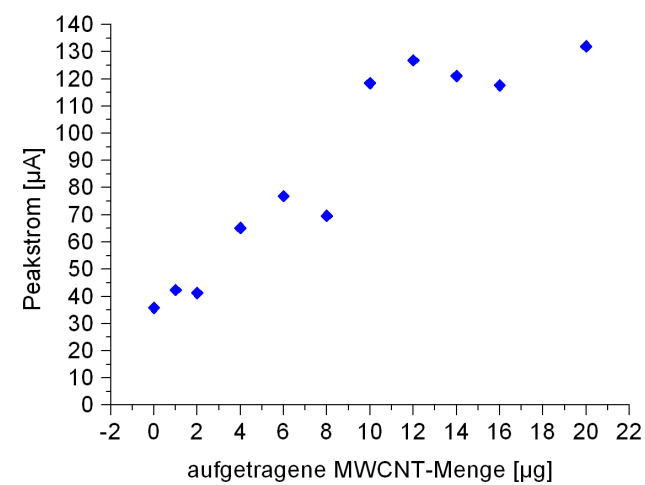

(a)

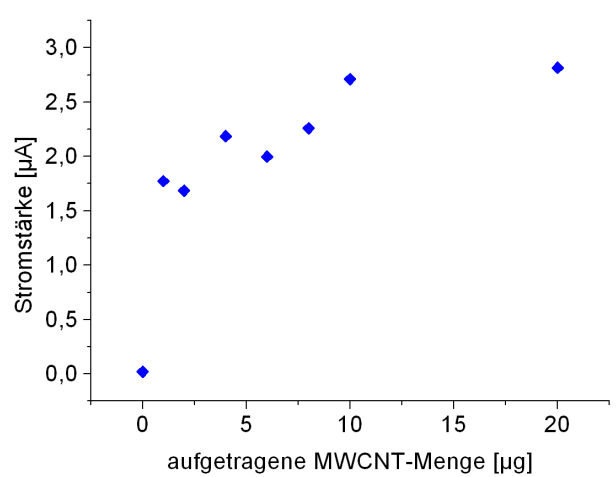

(b)

Abbildung 4.8: Abhängigkeit der Stromdichte von der aufgetragenen MWCNT-Menge mit Verfahren II $(\mathrm{n} * 1 \mu \mathrm{g}$ ); Stromstärke bei $250 \mathrm{mV}$ (gegen $\mathrm{Ag} / \mathrm{AgCl}$ ); MWCNT-modifizierte Goldelektrode; Messung in (a) $10 \mathrm{mM} \mathrm{KHCF}, 100 \mathrm{mM} \mathrm{CiP}, \mathrm{pH} 7 \mathrm{mit} \mathrm{CV}, 100 \mathrm{mV} / \mathrm{s}$, (b) $5 \mu \mathrm{M}$ BOD (in Lösung), $5 \mathrm{mM} \mathrm{CiP,} \mathrm{pH7} \mathrm{mit} \mathrm{LSV,} 10 \mathrm{mV} / \mathrm{s}$

fast ausschließlich, aber auch nicht vollständig die Goldoberfläche. Ab $2 \mu \mathrm{g}$ war die Goldoberfläche vollständig bedeckt, wobei die MWCNT-Schicht etwas darüber hinausragte, wie in Abb. 4.7 illustriert ist.

Die Abbildung 4.8 zeigt die Meßergebnisse für die Präparation mit Verfahren II. Auch hier ist deutlich eine Zunahme der Stromdichte mit steigender MWCNT-Menge zu verzeichnen. Ähnlich wie bei Verfahren I kam es ebenfalls zu einer Signalsättigung bei größeren Mengen an aufgetragenen Kohlenstoffnanoröhren (10-12 $\mu \mathrm{g})$. Die ansteigenden Meßssignale sind wiederum auf die wachsende Fläche zurückzuführen. Dabei spielen die erhöhte Oberflächenrauhigkeit, als auch die geometrische Ausdehnung eine Rolle. Die stagnierenden Signale könnten wie für Verfahren I mit dem Aufbau der schichtartigen Struktur und der alleinigen Reaktion von KHCF und BOD in einer Oberflächenschicht erklärt werden.

Da sich mit Verfahren I bei der Auftragung der Kohlenstoffnanoröhren höhere Stromstärken ergaben, wurden (wenn nicht anders angegeben) für die weiteren experimentellen Untersuchungen die Elektroden mit $2 * 4 \mu \mathrm{g}$ MWCNTs beschichtet. 


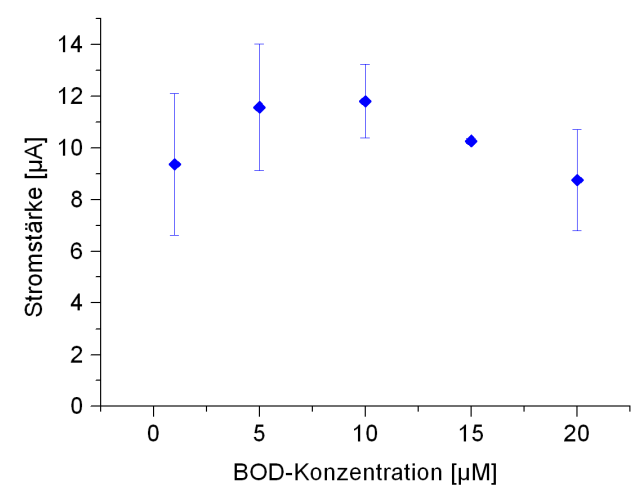

Abbildung 4.9: Einfluß der Enzymkonzentration während der Immobilisierung auf das Meßsignal; BOD kovalent gebunden an einer MWCNT-modifizierteb Goldelektrode; Messung in $100 \mathrm{mM} \mathrm{CiP,} \mathrm{pH} 7$ mit LSV, $10 \mathrm{mV} / \mathrm{s}$; Stromstärke bei $250 \mathrm{mV}$ (gegen $\mathrm{Ag} / \mathrm{AgCl}$ ); Fehlerbalken ergeben sich aus der Messung von 2 Elektroden für 1, 10, $15 \mu \mathrm{M}$ BOD, 3 Elektroden für $5,20 \mu \mathrm{M}$ BOD

\subsubsection{Enzymkonzentration während der Immobilisierung}

Die Auswirkung der Enzymkonzentration bei der kovalenten Anbindung wurde untersucht. Dafür wurde die MWCNT/Sulfo-GMBS-modifizierte Elektrode mit verschiedenen Proteinkonzentrationen für 1 Stunde bei Raumtemperatur inkubiert.

Aus Abb. 4.9 ist ersichtlich, daß bei einer Konzentration von etwa $10 \mu \mathrm{M}$ das größte Stromsignal erreicht wurde. Offensichtlich reicht diese Konzentration aus, um an alle zugänglichen Andockstellen für das Protein zu binden. Bei einer geringeren Konzentration werden wahrscheinlich nicht alle Bindungsstellen besetzt. Bei einer höheren Konzentration behindern sich möglicherweise die Proteine gegenseitig.

\subsection{Charakterisierung der Meßbedingungen}

\subsubsection{Einfluß des $\mathrm{pH}-$ Wertes}

Bei der Reduktion von Sauerstoff durch Bilirubinoxidase wird Wasser gebildet. Bei dieser Reaktion werden also auch Protonen benötigt.

$$
\frac{1}{2} \mathrm{O}_{2}+2 \mathrm{H}^{+}+2 e^{-} \leftrightharpoons \mathrm{H}_{2} \mathrm{O}
$$




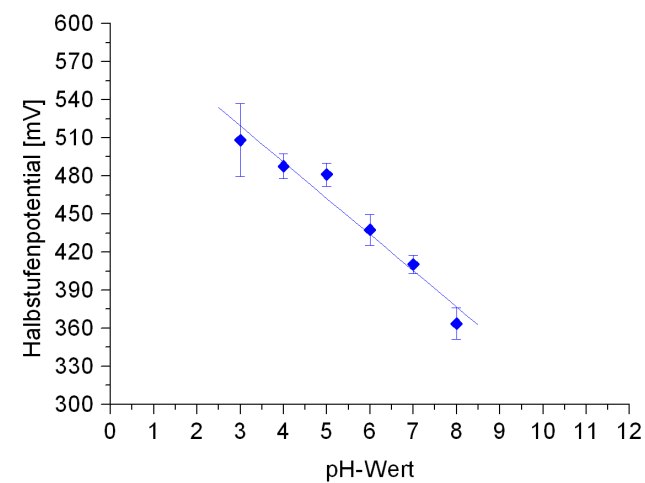

(a)

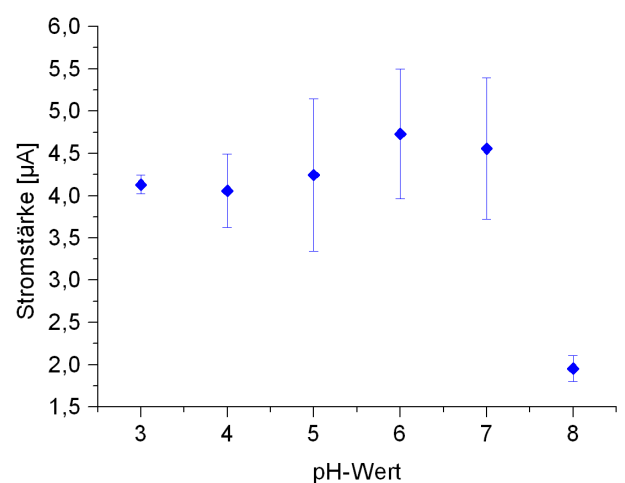

(b)

Abbildung 4.10: Einfluß des pH-Wertes des Meßpuffers; BOD kovalent gebunden an einer MWCNTmodifizierten Goldelektrode; Messung in $100 \mathrm{mM} \mathrm{CiP} \mathrm{mit} \mathrm{LSV,} 10 \mathrm{mV} / \mathrm{s}$; (a) Potentialverschiebung der Sauerstoffreduktion $\left(\mathrm{R}^{2}=0,9535\right)$; Potential gegen $\mathrm{Ag} / \mathrm{AgCl}$ (b) Abhängigkeit des katalytischen Stromes vom pH-Wert, maximale Stromstärke; Fehlerbalken ergeben sich aus der Messung von 3 Elektroden

Somit haben die zur Verfügung stehenden Hydroniumionen in der Lösung einen Einfluß auf die Reaktion. Bei abnehmendem pH-Wert steht eine erhöhte Hydroniumionenkonzentration in der Lösung zur Verfügung. Das hat zur Folge, das weniger Kraft, also eine geringere Überspannung nötig ist, um die Reaktion zu forcieren. Bei höherer Hydroniumionenkonzentration ist daher eine kleinere Überspannung notwendig bis die Reduktion des Sauerstoffs beginnt.

Die Halbstufenpotentiale von 3 Meßreihen wurden ausgewertet und über dem pH-Wert aufgetragen (Abb. 4.10a). Die lineare Regression der Datenpunkte ergab eine durchschnittliche Steigung von $-28,6 \mathrm{mV} / \mathrm{pH}\left(\mathrm{R}^{2}=0,9535\right)$. Diese Abhängigkeit entspricht der Nernst'schen Gleichung und beschreibt einen Prozeß, bei dem 2 Elektronen übertragen werden.

Die katalytische Aktivität des Enzyms ist ebenfalls vom pH-Wert abhängig. Bei pH 6 erreichte der katalytische Strom der BOD-MWCNT-Goldelektrode unter Luftsättigung sein Maximum, wie in Abb. 4.10b zu sehen. Bei pH 7 war der katalytische Strom fast genauso hoch. Dies zeigt, daß das Enzym in der Lage ist, im physiologischen pH-Bereich ( $\mathrm{pH} 6-7$ ) mit höchster Aktivität zu arbeiten. Das ist vor allem für biomedizinische 
Anwendungen von großem Vorteil. Bei pH 8 ist schon ein deutlicher Aktiviätsverlust zu verzeichnen, was möglicherweise auf eine Konformationsänderung der Proteinstruktur hinweist. In der Literatur wird für die katalytische Aktivität von BOD in Lösung gegenüber Bilirubin ein pH-Optimum von $\mathrm{pH}$ 7,5 angegeben.[27] Somit scheint das pHOptimum der Bilirubinoxidase an der MWCNT-modifizierten Elektrode etwas in den sauren Bereich verschoben zu sein. Der optimale pH-Wert eines Enzyms kann durch seine Immobilisierung verändert werden, da das Protein anderen Wechselwirkungen unterliegt als in Lösung. Weiterhin ist das pH-Optimum auch vom Elektronendonor für das Enzym abhängig, was in diesem Fall nicht Bilirubin ist, sondern die MWCNT-modifizierte Goldelektrode.

\subsubsection{Einfluß der lonenstärke des Meßpuffers}

Als weiterer Meßparameter wurde die Ionenstärke des Meßpuffers untersucht und Messungen in CiP-Puffer verschiedener Konzentration durchgeführt.

Anhand der Stromsignale in Abbildung 4.11a ist zu erkennen, daß das Elektrodensystem in einem weiten Bereich der Pufferkonzentration ohne Einschränkung arbeitete. Ab einer Elektrolytkonzentration von $10 \mathrm{mM}$ blieb das voltammetrische Meßsignal etwa gleich hoch. In $1 \mathrm{mM}$ Meßspuffer wurde jedoch ein deutlich kleinerer Strom detektiert. Bei sehr kleinen Ionenkonzentrationen ist der Ladungstransport in der Elektrolytlösung gestört, was einen höheren Lösungswiderstand zur Folge hat. Bei konstanter Spannung ist die Stromstärke umgekehrt proportional zum Ohmschen Widerstand.

Die Pufferkonzentration hat jedoch auch einen Einfluß auf das Startpotential der Sauerstoffkatalyse (Abb. 4.11b). Je kleiner die Konzentration ist, desto negativer wird das Startpotential. Bei konstanter Stromstärke ist die Spannung direkt proportional zum Ohmschen Widerstand. Das heißt, die größere Überspannung zum Starten der Sauerstoffkatalyse kann vor allem mit einem erhöhten Durchtrittswiderstand an der Phasengrenze von der Elektrodenbeschichtung zur BOD erklärt werden. Bei geringerer Ionenkonzentration im Puffer scheint der heterogene Elektronentransfer über diese Phasengrenze stärker behindert $\mathrm{zu}$ werden. Möglicherweise beeinflußt die Ionenkonzentration in der Lösung aber auch die Konformation von Bilirubinoxidase, sodaß mehr Kraft (mehr Überspan- 


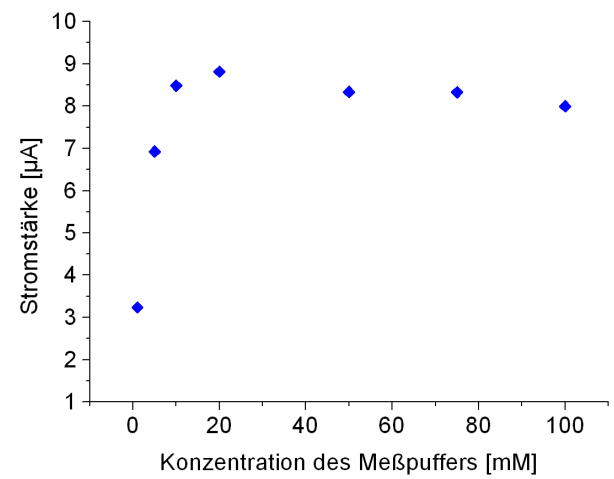

(a)

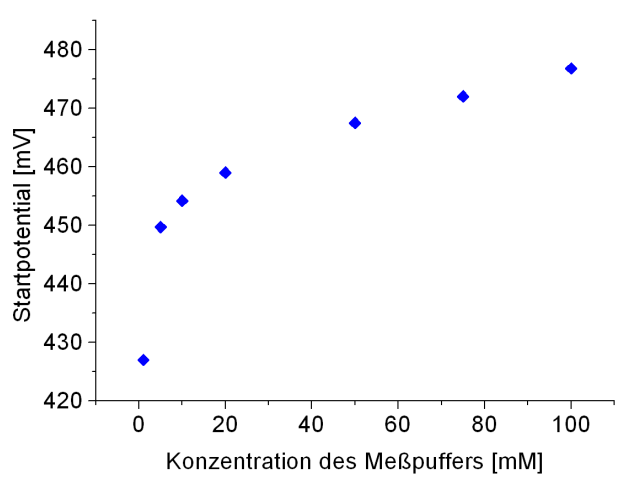

(b)

Abbildung 4.11: Einfluß der Ionenstärke des Meßpuffers; BOD kovalent gebunden an einer MWCNTmodifizierten Goldelektrode; Messung in CiP, pH 7 mit LSV, $10 \mathrm{mV} / \mathrm{s}$; (a) Abhängigkeit des Stromsignals, Stromstärke bei $250 \mathrm{mV}$; (b) Abhängigkeit des Startpotentials; Potentiale gegen $\mathrm{Ag} / \mathrm{AgCl}$

nung) aufgewendet werden muß, um die bioelektrokatalytische Reaktion zu forcieren. Die voltammetrischen Meßkurven (siehe Abb.4.12) zeigen eine Abflachung der Peakform bei abnehmender Pufferkonzentration, was wegen dem erhöhten Durchtrittswiderstand wahrscheinlich nicht nur zu einer Verzögerung, sondern auch zu einer Verlangsamung des heterogenen Elektronentransfers zur BOD und der damit verbundenen Sauerstoffreduktion führte.

\subsubsection{Lagerstabilität}

Zur Untersuchung der Lagerstabilität wurden 2 Experimente durchgeführt. Eine Elektrode mit kovalent gebundener Bilirubinoxidase wurde in $100 \mathrm{mM} \mathrm{CiP-Puffer,} \mathrm{pH} \mathrm{7,} \mathrm{eine}$ zweite in $5 \mathrm{mM} \mathrm{CiP,} \mathrm{pH} 7$ bei $5^{\circ} \mathrm{C}$ gelagert und zwischendurch immer wieder gemessen.

Wie zu erwarten nahm der katalytische Strom mit der Lagerdauer ab (siehe Abb. 4.13. Das voltammetrische Meßssignal fiel innerhalb der ersten 3 Tage auf etwa $8 \mu \mathrm{A}$, arbeitete jedoch relativ stabil für reichlich eine Woche in diesem Bereich. Mit längerer Lagerdauer sank die Signalstärke stetig weiter ab. Am 24. und 57. Tag wurden zusätzlich Kontrollmessungen mit der Elektrode in Ar-gesättigtem Puffer durchgeführt. Selbst nach 


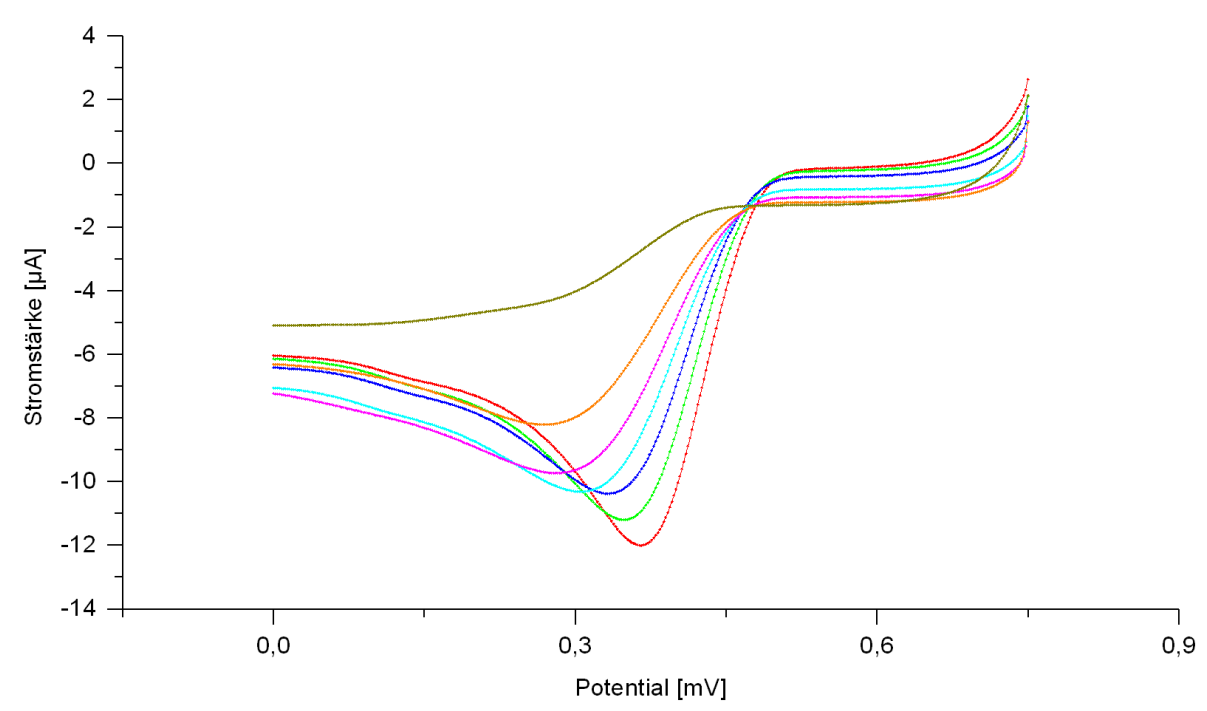

Abbildung 4.12: Abhängigkeit der voltammetrischen Messung von der Ionenstärke im Meßpuffer; BOD kovalent gebunden an einer MWCNT-modifizierten Goldelektrode; Messung in $\mathrm{CiP}, \mathrm{pH} 7 \mathrm{mit} \mathrm{LSV} ;(-) 100 \mathrm{mM} \mathrm{CiP},(-) 75 \mathrm{mM} \mathrm{CiP},(-) 50 \mathrm{mM} \mathrm{CiP},(-) 20 \mathrm{mM}$ $\mathrm{CiP},(-) 10 \mathrm{mM} \mathrm{CiP,} \mathrm{(-)} 5 \mathrm{mM} \mathrm{CiP,} \mathrm{(-)} 1 \mathrm{mM} \mathrm{CiP}$; Potential gegen $\mathrm{Ag} / \mathrm{AgCl}$

fast 2 Monaten Lagerung und wiederholten Messungen konnte im luftgesättigten Puffer ein katalytischer Strom gemessen werden, der sich deutlich von dem Meßsignal in Argesättigtem Puffer unterschied. Damit erwies sich die an einer MWCNT-modifizierten Goldelektrode kovalent gebundene BOD im Vergleich zu vielen anderen Proteinen als sehr stabil.

Wie in Abbildung $4.14 \mathrm{zu}$ sehen, lieferte die in $5 \mathrm{mM}$ gelagerte Elektrode innerhalb der ersten 3 Tage noch ein relativ stabiles Signal. Ab dem 4. Tag der Lagerung nahm das voltammetrische Meßsignal stetig ab, was im Vergleich zu der in $100 \mathrm{mM} \mathrm{CiP}$ gelagerten Elektrode sogar etwas stärker erfolgte. Nach 27 Tagen wurde ebenfalls eine Kontrollmessung in Ar-gesättigtem Puffer durchgeführt, deren Meßssignal noch deutlich kleiner als das in luftgesättigtem Puffer ausfiel.

Die Belegung der Kohlenstoffnanoröhren mit Thiolgruppen lag bei lediglich 0,5-1\% (Angabe des Herstellers, Nanocyl S.A., Belgien), so daß durchaus nahezu alle zugänglichen Thiolgruppen eine Bindung mit Bilirubinoxidase eingegangen waren. Zwischen 


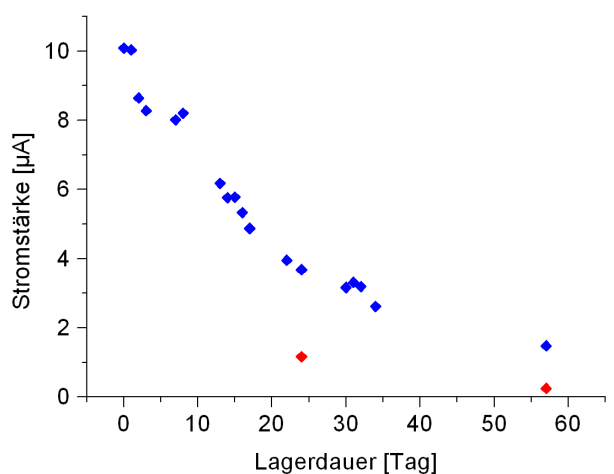

(a)

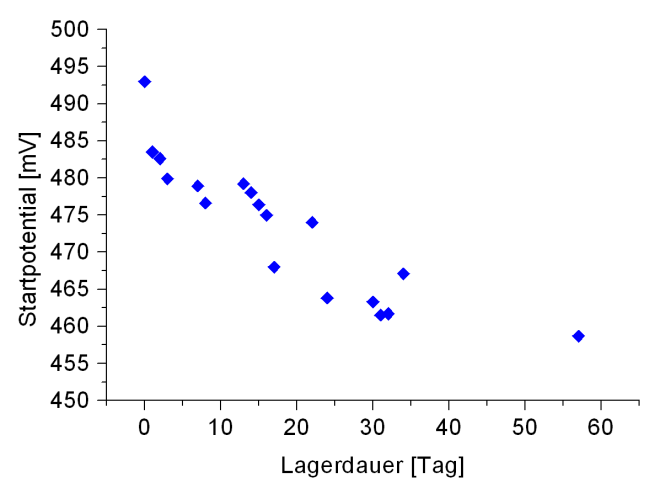

(b)

Abbildung 4.13: Lagerstabilität in $100 \mathrm{mM} \mathrm{CiP-Puffer,} \mathrm{pH} 7$ bei $5^{\circ} \mathrm{C}$; BOD kovalent gebunden an einer MWCNT-modifizierten Goldelektrode; Messung in $100 \mathrm{mM} \mathrm{CiP,} \mathrm{pH7} \mathrm{mit} \mathrm{LSV;}$ (a) katalytischer Strom in $\diamond$ luftgesättigtem Puffer, $\diamond$ Ar-gesättigtem Puffer, Stromstärke bei $250 \mathrm{mV}$; (b) Startpotential; Potentiale gegen $\mathrm{Ag} / \mathrm{AgCl}$

diesen Bindungsstellen verblieb jedoch wahrscheinlich genügend Platz, so daß weitere Proteine zusätzlich an der MWCNT-Oberfläche adsorbieren konnten. Eine adsorptive Bindung ist deutlich schwächer als eine kovalente und kann somit relativ schnell wieder gelöst werden. Vermutlich "blutete"1 die in $100 \mathrm{mM}$ Puffer gelagerte Elektrode in der Anfangszeit aus, wobei vorwiegend adsorptiv gebundene Proteine wieder abgelöst wurden und so zu dem Signalverlust führten. Der Signalverlust im weiteren Verlauf der Lagerung ist auf eine zunehmende Inaktivierung der Enzymmoleküle zurückzuführen. Bei der $5 \mathrm{mM}$ gelagerten Elektrode war das Ausbluten aufgrund der geringen Pufferkonzentration scheinbar nicht ganz so stark. Da die Messungen in $100 \mathrm{mM}$ Puffer erfolgten, war diese Elektrode durch den Wechsel der Ionenstärke im Puffer einer zusätzlichen Belastung ausgesetzt, was den etwas steileren Abfall der Meßwerte im Vergleich zu der in 100 mM Puffer gelagerten Elektrode erklären würde. Möglicherweise benötigt Bilirubinoxidase eine etwas höhere Ionenkonzentration für optimale Bedingungen.

Enzyme sind relativ empfindliche Biomoleküle. Ein großer Schwachpunkt ist dabei meist die Stabilität. Die an der MWCNT-modifizierten Goldelektrode kovalent gebun-

\footnotetext{
${ }^{1}$ Als "Ausbluten" wird in der Biosensorik der Verlust von Molekülen des Erkennungs- bzw. Transducerelements im Sensorsystem bezeichnet.
} 


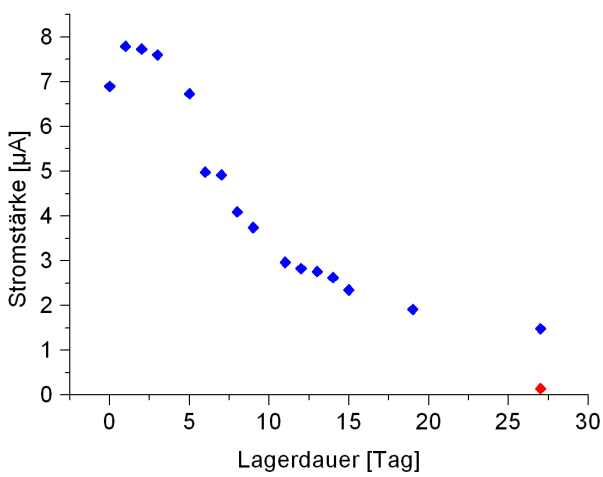

(a)

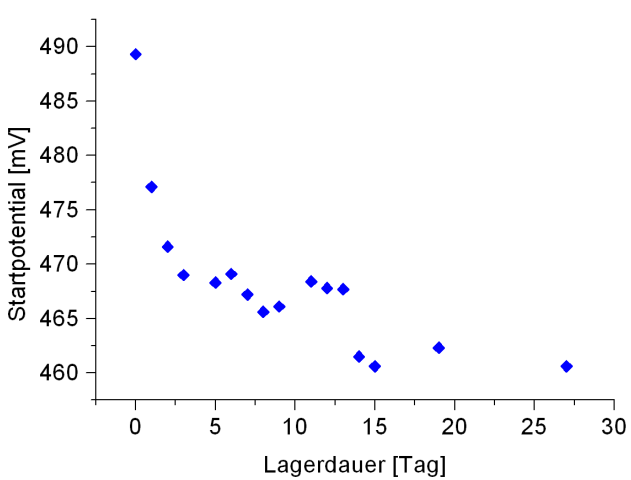

(b)

Abbildung 4.14: Lagerstabilität in $5 \mathrm{mM}$ CiP-Puffer, $\mathrm{pH} 7$ bei $5{ }^{\circ} \mathrm{C}$; BOD kovalent gebunden an einer MWCNT-modifizierten Goldelektrode; Messung in $100 \mathrm{mM} \mathrm{CiP,} \mathrm{pH7} \mathrm{mit} \mathrm{LSV;} \mathrm{(a)}$ katalytischer Strom in luftgesättigtem Puffer, $\downarrow$ Ar-gesättigtem Puffer, Stromstärke bei $250 \mathrm{mV}$; (b) Startpotential; Potentiale gegen $\mathrm{Ag} / \mathrm{AgCl}$

dene Bilirubinoxidase erweist sich dahingehend als sehr robust und würde sich diesbezüglich somit sehr gut für die Entwicklung sensorischer Anwendungen eignen.

In Abbildung 4.15 ist zu erkennen, daß sich während des Lagerungszeitraumes der Elektrode der Kurvenverlauf änderte. Die Peakform wandelte sich innerhalb der ersten paar Tage in eine abgeflachte Kurve. In Abschnitt 4.1 wurde diskutiert, daß der peakförmige Meßkurvenverlauf möglicherweise auf 2 Immobilisierungszustände des Enzyms auf der Elektrode zurückzuführen ist. Wenn innerhalb der ersten Tage der Lagerung ein Großteil der adsorbierten Proteine abgelöst wurden, war BOD vorwiegend nur noch kovalent gebunden. Damit würde keine Überlagerung mehr von 2 unterschiedlichen HETProzessen eintreten. Die Änderung des Kurvenverlaufs unterstützt also diese These.

Da Kohlenstoffnanoröhren zur Gasadsorption neigen, ist möglicherweise in der MWCNTSchicht der Elektrode nach der Präparation ein zusätzliches Sauerstoffreservoir vorhanden. Somit würden bei den ersten Messungen auch mehr Sauerstoffmoleküle für die bioelektrokatalytische Reduktion durch BOD zur Verfügung stehen, die während der Messung nicht nur aus der Lösung, sondern auch für einige Zeit in höherer Konzentration aus Richtung der MWCNT-Schicht zum Enzym diffundieren könnten. 


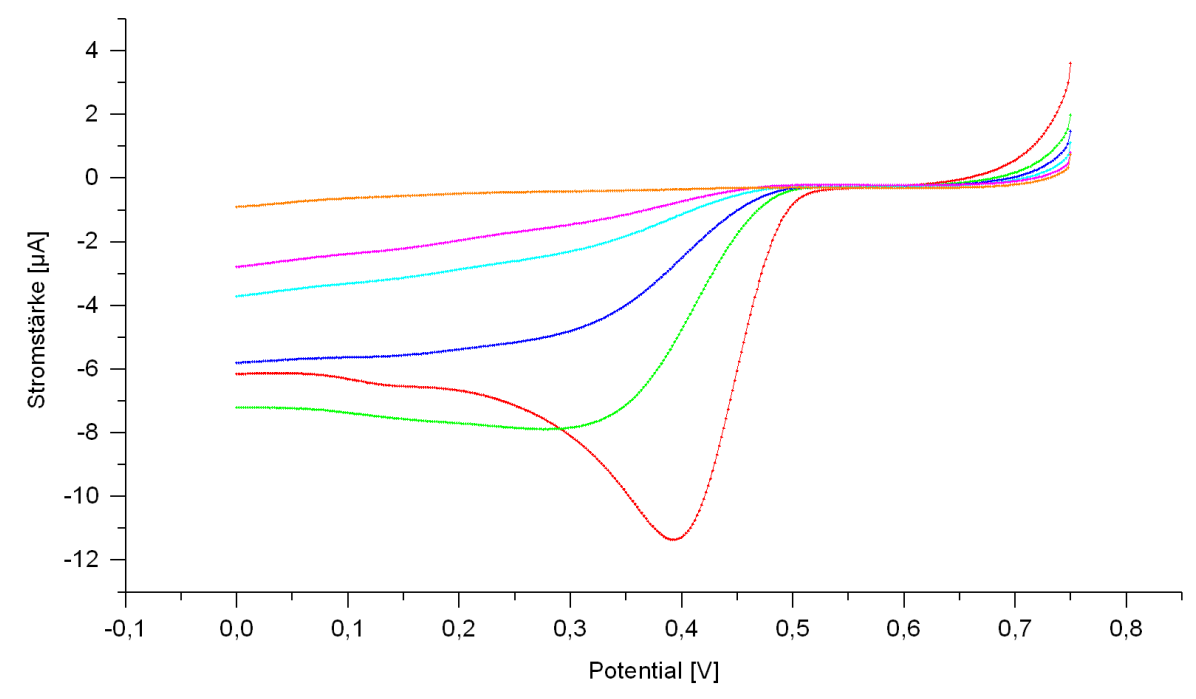

Abbildung 4.15: Lagerstabilität in $5 \mathrm{mM} \mathrm{CiP,} \mathrm{pH} 7$ bei $5^{\circ} \mathrm{C}$, Meßkurven einiger Meßtage; BOD kovalent gebunden an einer MWCNT-modifizierten Goldelektrode; Messung in $100 \mathrm{mM}$ CiP, pH7 mit LSV, luftgesättigt: (-) Tag 0, (-) Tag 3, (-) Tag 7, (-) Tag 15, (-) Tag 27, Ar-gesättigt: (-) Tag 27; Potential gegen $\mathrm{Ag} / \mathrm{AgCl}$

Um einen Hinweis auf die Kinetik der Elektrodenreaktion zu erhalten, wurden voltammetrische Messungen mit einer frisch präparierten und der in $5 \mathrm{mM}$ CiP gelagerten Elektrode sowohl in einer gerührten, als auch ungerührten Pufferlösung durchgeführt. Abbildung 4.16a läßt bei einer frisch präparierten Elektrode auf einen diffusionslimitierten Gesamtprozeß schließen. Bei diffusem Stofftransport trat bei großer Überspannung ein Gleichgewichtszustand ein und das Meßsignal erhöhte sich nicht weiter. Bei Durchmischung wird die Diffusionsschichtdicke vor der Elektrode stark verringert. Die Sauerstoffkonzentration wirkt nicht mehr limitierend, wodurch das Meßsignal bei Überspannung weiter stark anstieg. Die gerührten und ungerührten Messungen der in $5 \mathrm{mM}$ gelagerten Elektrode ergaben Meßkurven, die relativ ähnlich zueinander ausfielen (siehe Abb. 4.16b). Das spricht für eine deutliche Verlangsamung der Elektrodenreaktion. 


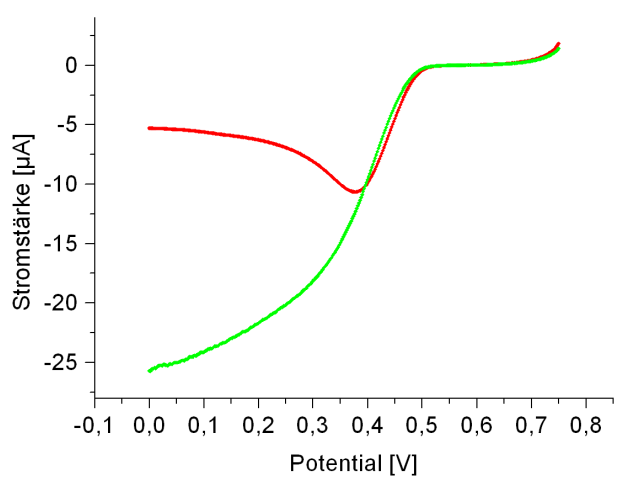

(a)

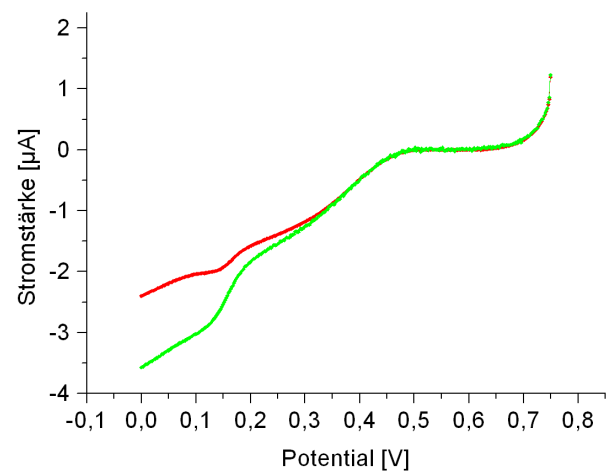

(b)

Abbildung 4.16: Messung des katalytischen Stromes in gerührter und ungerührter Pufferlösung, BOD kovalent gebunden an einer MWCNT-modifizierten Goldelektrode, LSV in $100 \mathrm{mM}$ $\mathrm{CiP}, \mathrm{pH} 7 \mathrm{mit} 10 \mathrm{mV} / \mathrm{s}$; jeweils (-) ungerührt, (-) gerührt; (a) Elektrode unmittelbar nach Präparation, (b) Elektrode in $5 \mathrm{mM}$ CiP, pH 729 Tage bei $5^{\circ}$ Cgelagert; Potentiale gegen $\mathrm{Ag} / \mathrm{AgCl}$

\subsection{Charakterisierung der analytischen Eigenschaften}

\subsubsection{Sauerstoffkonzentration}

Das hier verwendete Elektrodensystem kann nicht nur für das Studium des heterogenen Elektronentransfers, sondern prinzipiell auch als Sensor für die Sauerstoffkonzentration in Lösung verwendet werden. Dazu wurden Experimente mit Puffer durchgeführt, in dem durch Entgasung und längerer Argon-Begasung der Luftsauerstoff entfernt wurde. Anaerober und luftgesättigter Puffer wurden in bestimmten Verhältnissen zueinander gemischt und als Meßpuffer verwendet.

Wie in Abbildung 4.17 zu sehen, korrelierte der katalytische Strom sehr gut mit dem Anteil des luftgesättigten Puffers. In dem Puffer ohne Luftsauerstoff konnte bei $250 \mathrm{mV}$ (gegen $\mathrm{Ag} / \mathrm{AgCl}$ ) kein katalytischer Strom, sondern nur der Ladestrom detektiert werden. Die Höhe des Ladestroms wurde bei der Auswertung von den restlichen Meßwerten abgezogen. Mit steigendem Anteil des luftgesättigten Puffers konnte ein zunehmender katalytischer Strom detektiert werden. Die vollständig lineare Abhängigkeit im gesamten gemessenen Sauerstoffkonzentrationsbereich (bis etwa $250 \mu \mathrm{M}$ ) zeigt, daß keine Limitie- 


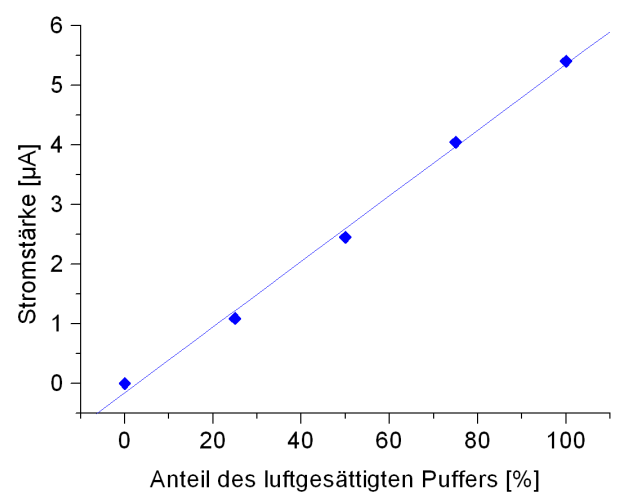

Abbildung 4.17: Messung der Sauerstoffkonzentration im Meßpuffer; BOD kovalent gebunden an einer MWCNT-modifizierten Goldelektrode, LSV in $100 \mathrm{mM} \mathrm{CiP,} \mathrm{pH} 7 \mathrm{mit} 10 \mathrm{mV} / \mathrm{s}$; Stromstärke bei $250 \mathrm{mV}$ (gegen $\mathrm{Ag} / \mathrm{AgCl}) ;(\mathrm{R}=0,99785)$

rung im Ansprechen des Sensorsystems durch das Substrat $\left(\mathrm{O}_{2}\right)$ auftrat.

Im Vergleich zu anderen Messungen in luftgesättigtem Puffer fiel der katalytische Strom niedriger aus. Durch ein Kontrollexperiment mit Luft wurde festgestellt, daß die Begasung des Puffers in der Meßzelle mit eingebauter, präparierter Elektrode eine starke hydrodynamische Belastung für die Elektrodenbeschichtung (BOD) darstellte. Die Folge war mit hoher Wahrscheinlichkeit ein Verlust an Enzymmolekülen und damit auch die Beeinträchtigung des Meßssignals. Das Experiment wurde jedoch mehrfach durchgeführt und war reproduzierbar. Die Stromdichten für dieses Experiment lagen im Bereich von $200-300 \mu \mathrm{A} / \mathrm{cm}^{2}$.

Bei der Bewertung und dem Vergleich von Stromstärken bei Messungen in luftgesättigtem Puffer muß auch die Temperatur in Betracht gezogen werden. Zum einen hat BOD ein Aktivitätsmaximum bei $40^{\circ} \mathrm{C}$.[27] Zum anderen sinkt die Sauerstoffkonzentration mit steigender Temperatur in wäßrigen Lösungen. Während der experimentellen Phase sind Temperaturunterschiede von bis zu $10^{\circ} \mathrm{C}$ aufgetreten, was Schwankungen bei den Stromsignalen in luftgesättigtem Puffer verursacht hat.

\subsubsection{Wechselwirkung mit Bilirubin}

Bilirubin ist das natürliche Substrat von Bilirubinoxidase und wird durch das Enzym zu Biliverdin oxidiert. Die dabei abgegebenen Elektronen werden auf Sauerstoff bei der 
Reduktion zu Wasser übertragen. Um die Wechselwirkung von BOD mit Bilirubin zu untersuchen, wurde beobachtet, wie sich der katalytische Strom der Sauerstoffreduktion in Anwesenheit von Bilirubin im Meßpuffer änderte.

Abbildung 4.18a zeigt einen abnehmenden katalytischen Strom der Sauerstoffreduktion mit zunehmender Bilirubin-Konzentration. Ab etwa $80 \mathrm{mM}$ Bilirubin im Meßspuffer blieb der katalytische Strom konstant. Zwischen dem Elektronentransfer von der Elektrode und von Bilirubin auf das Enzym herrscht eine Konkurrenzsituation. Da mit zunehmender Bilirubin-Konzentration immer mehr Enzyme mit Substrat reagieren, werden immer weniger Elektronen von der Elektrode akzeptiert. Die Michaelis-Menten-Konstante ist $0,12 \mathrm{mM}$ für die Reaktion von BOD mit Bilirubin bei $\mathrm{pH}$ 8.[27] Damit waren die hier verwendeten Bilirubinkonzentrationen im Bereich der Substratsättigung. In diesem Konzentrationsbereich wäre eigentlich ein Absinken des katalytischen Stromes auf nahezu Null zu erwarten gewesen. Es verblieb jedoch ein deutliches Stromsignal. Das heißt, es wurden immer noch Elektronen von der Elektrode auf Bilirubinoxidase übertragen. Trotz einem sehr hohen Überschuß an Bilirubin war ein direkter Elektronentransfer von der MWCNT-modifizierten Elektrode zur BOD möglich. Das läßt darauf schließen, daß ein Teil der Enzyme nicht in der Lage war, mit Bilirubin zu interagieren. Möglicherweise orientierten sich diese Enzymmoleküle bei der Immobilisierung derart, daß eine Elektronenübertragung nur von der Elektrode möglich war und kein Bilirubin binden konnte. Der andere Teil der Enzyme war in der Lage, mit Bilirubin zu interagieren, was den Elektronentransfer von der Elektrode verhinderte. Möglicherweise konnten diese Moleküle ihre Orientierung ändern. Durch die Immobilisierung mit einem crosslinker könnte eine solche Bewegungsfreiheit möglich sein. Die sehr hohe Bilirubinkonzentration, die nötig war, um den DET zu verdrängen, spricht dafür, daß die Elektronen von der MWCNT-modifizierten Elektrode wahrscheinlich auf das T1-Zentrum der BOD übertragen werden, welches als natürlicher Elektronenakzeptor für Bilirubin fungiert.

Das Startpotential der bioelektrokatalytischen Sauerstoffreduktion lag bei etwa $490 \mathrm{mV}$ (gegen $\mathrm{Ag} / \mathrm{AgCl}$ ) und veränderte sich durch die Zugabe von Bilirubin nicht (siehe Abb. $4.18 \mathrm{~b})$. 


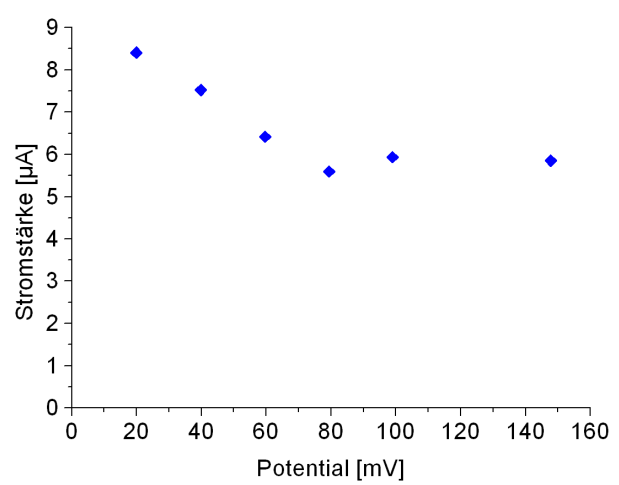

(a)

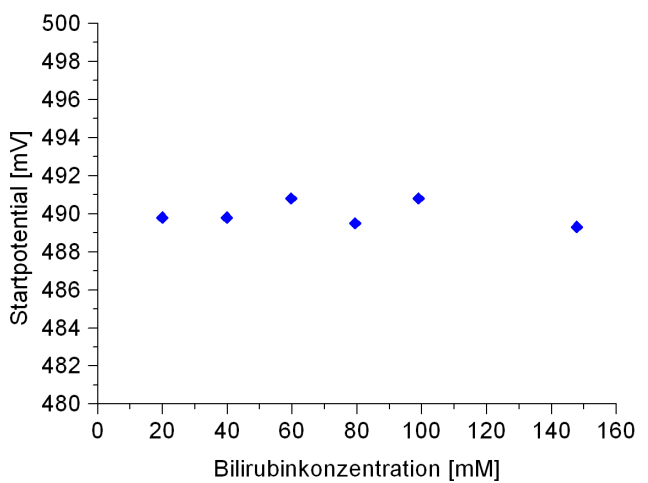

(b)

Abbildung 4.18: Einfluß von Bilirubin auf den Reduktionsstrom von $\mathrm{O}_{2}$, BOD kovalent an MWCNTmodifizierter Goldelektrode, LSV in $100 \mathrm{mM} \mathrm{CiP}, \mathrm{pH} 7 \mathrm{mit} 10 \mathrm{mV} / \mathrm{s}$, (a) katalytischer Strom, Stromstärke bei $250 \mathrm{mV}$; (b) Startpotential; Potentiale gegen $\mathrm{Ag} / \mathrm{AgCl}$

\subsubsection{Wechselwirkung mit Inhibitoren}

Aus der Literatur sind Flourid- $\left(\mathrm{F}^{-}\right)$und Azid-Ionen $\left(\mathrm{N}_{3}^{-}\right)$als Inhibitoren für Kupferproteine bekannt.[3] Deshalb wurde die Veränderung des katalytischen Stromes bei Zugabe von $\mathrm{NaF}$ und $\mathrm{NaN}_{3}$ untersucht.

Es ist anhand der Abbildung 4.19a deutlich zu erkennen, daß der katalytische Strom mit zunehmender NaF-Konzentration abnahm und sich dabei scheinbar einem Grenzwert (ungleich Null) näherte. Natriumflourid ist also in der Lage, die katalytische Aktivität von BOD zu hemmen. Mit aller Wahrscheinlichkeit dringen Flourid-Ionen zu den beiden katalytischen Zentren vor und komplexieren dort die Kupferionen.[3, 28] Dadurch wird zum einen der DET zum T1-Kupfer unterbunden, zum anderen kann weniger Sauerstoff am trinuklearen Cluster gebunden und reduziert werden. Das Startpotential (Abb.4.19b) verschob sich mit zunehmender NaF-Konzentration in der Lösung zu immer negativeren Werten und wies dabei eine lineare Abhängigkeit auf. Durch die Komplexierung des Kupfers durch die Fluoridionen änderte sich das Redoxpotential des betreffenden Kupferzentrums. Außerdem konnten vermutlich durch eine höhere Überspannung Fluorid-Ionen vom katalytischen Zentrum verdrängt und Elektronen zur Reduktion des Sauerstoffs weiter übertragen werden. Das würde auch die unvollständige Inhibierung 


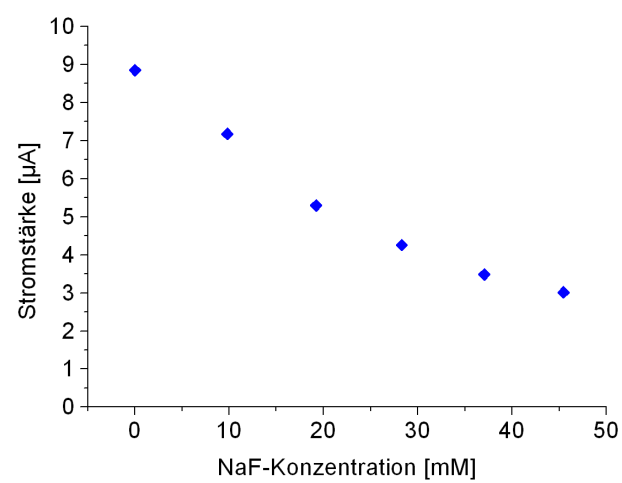

(a)

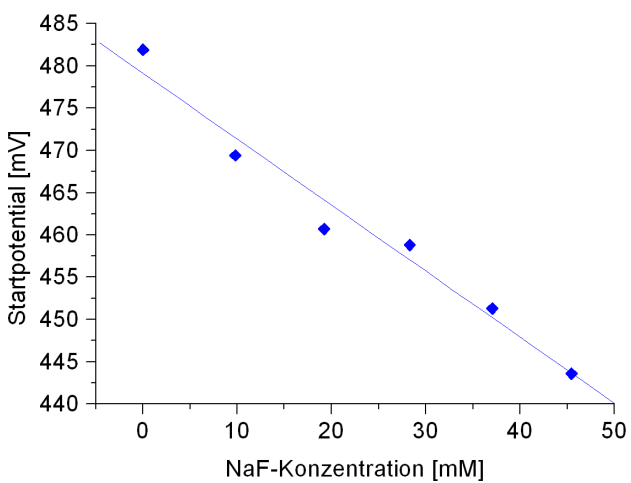

(b)

Abbildung 4.19: Einfluß von NaF auf die Sauerstoffreduktion, LSV in luftgesättigtem CiP, pH 7, BOD kovalent gebunden an einer MWCNT-modifizierten Goldelektrode; (a) katalytischer Strom, Stromstärke bei $250 \mathrm{mV}$; (b) Startpotential $(\mathrm{R}=-0,9845)$; Potentiale gegen $\mathrm{Ag} / \mathrm{AgCl}$

bei höheren NaF-Konzentrationen erklären.

Anhand der Kurvenform kann deutlich eine Veränderung im Reaktionsmechanismus festgestellt werden. Wie schon in Abschnitt 4.3.3 diskutiert, steht die Änderung des Kurvenverlaufes vermutlich im Zusammenhang mit einer Änderung im Verhältnis oder gar dem Wechsel von limitierendem und nicht limitierendem Schritt in der Gesamtreaktion. Dieses Experiment bestätigt diese Interpretation dahingehend, daß NaF als Inhibitor die katalytische Reaktion stark verlangsamt. Die Fluoridionen komplexieren zum einen die Cu-Ionen in BOD, zum anderen stören sie als negative Ladungsträger in Elektrodennähe auch den direkten Elektronentransfer von der Elektrode zum Enzym.

Ein ähnliches Verhalten der Meßwerte trat bei Zugabe von Natriumazid auf, wie in den Abbildungen 4.21 a und b zu sehen ist. Abbildung 4.20 zeigt die voltammetrischen Meßkurven der LSV-Messungen bei Zugabe von Natriumfluorid. Der katalytische Strom nahm mit zunehmender $\mathrm{NaN}_{3}$-Konzentration exponentiell ab, näherte sich aber hier fast dem Null-Wert. Das Startpotential wies ebenfalls eine lineare Abhängigkeit auf, die ebenfalls auf die Veränderung des Redoxpotentials des betreffenden Kupferzentrums hinweist. Die Azidionen waren jedoch in der Lage, die bioelektrokatalytische Sauerstoffreduktion nahzu vollständig zu inhibieren. 


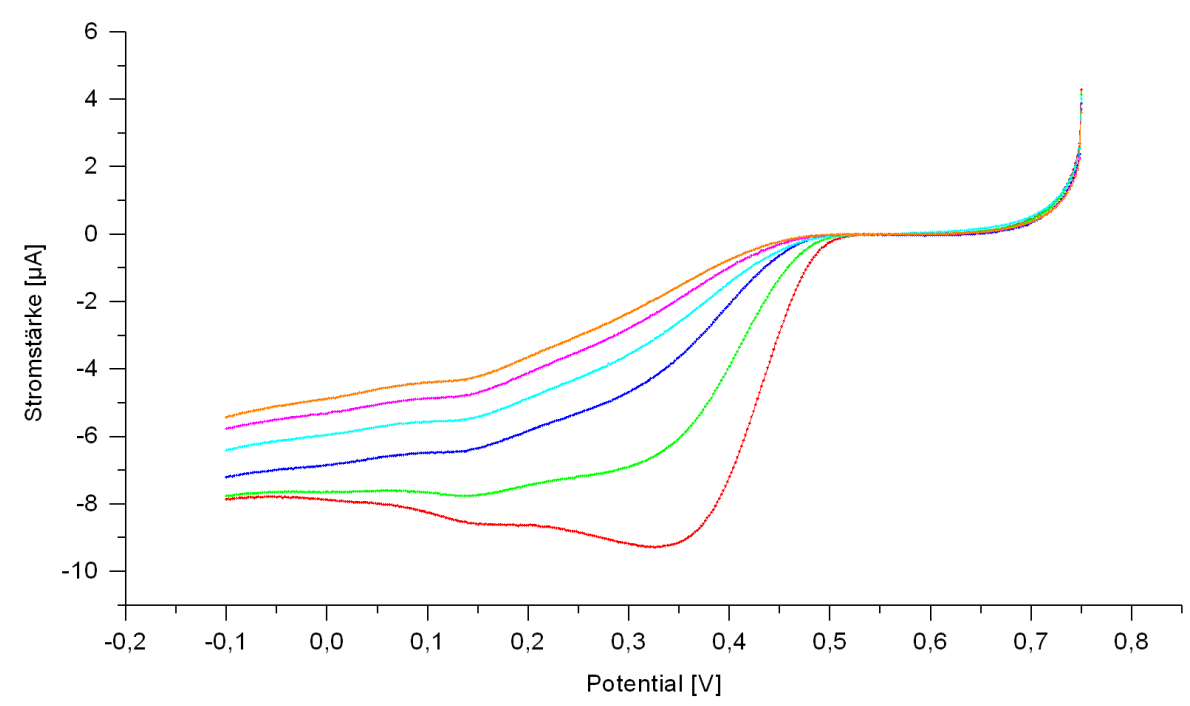

Abbildung 4.20: Einfluß von NaF auf die Sauerstoffreduktion, LSV in luftgesättigtem CiP, pH 7, BOD kovalent gebdunden an einer MWCNT-modifizierten Goldelektrode; $(-)$ ohne, $(-)$ 9,8 mM, (-) 19,23 mM, (-) 28,3 mM, (-) 37,04 mM, (-) 45,45 mM NaF; Potentiale gegen $\mathrm{Ag} / \mathrm{AgCl}$

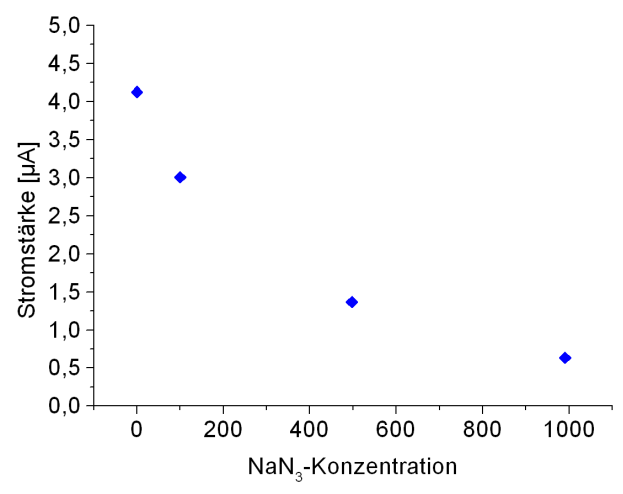

(a)

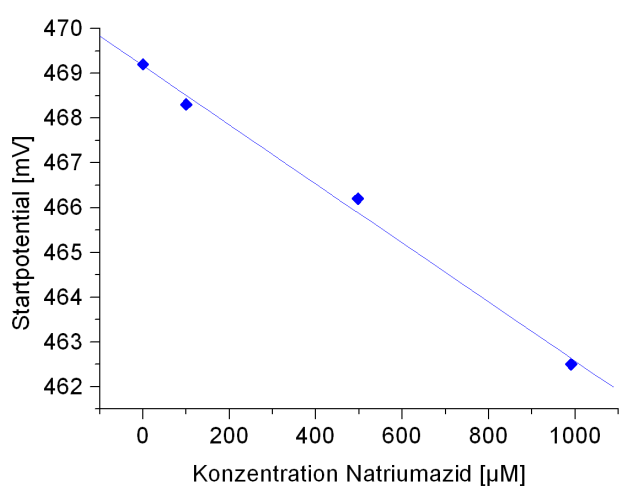

(b)

Abbildung 4.21: Einfluß von $\mathrm{NaN}_{3}$ auf die Sauerstoffreduktion, LSV in luftgesättigtem $\mathrm{CiP}, \mathrm{pH} 7$, BOD kovalent gebunden an einer MWCNT-modifizierten Goldelektrode; (a) katalytischer Strom, Stromstärke bei $250 \mathrm{mV}$; (b) Startpotential $(\mathrm{R}=-0,99695)$; Potentiale gegen $\mathrm{Ag} / \mathrm{AgCl}$ 


\subsection{Elektrochemisches Verhalten unter anaeroben Bedingungen}

\subsubsection{Direkte Redoxreaktion eines Kupferzentrums}

Bisher wurde das elektrochemische Verhalten von Bilirubinoxidase meist nur unter aeroben Bedingungen untersucht, da unter Sauerstoffausschluß kein oder fast kein Elektronentransfer zu verzeichnen war. Weigel et al. [24] war es jedoch gelungen, unter anaeroben Bedingungen den direkten Redoxprozeß eines Kupferzentrums von Bilirubinoxidase an Kohlenstoffelektroden zu beobachten.

In der vorliegenden Arbeit wurde eine Redox-Umwandlung von immobilisierter BOD an einer MWCNT-modifizierten Goldelektrode durchgeführt. Um eine hohe Konzentration von BOD vor der Elektrode zu gewährleisten, erfolgte die Fixierung des Enzyms zunächst mit einer Dialysemembran (MWCO $8 \mathrm{kDa}$ ). Aus der zyklovoltammetrischen Messung (siehe Abb. 4.22) ergab sich ein formales Potential von etwa $470 \pm 10 \mathrm{mV}$ gegen $\mathrm{Ag} / \mathrm{AgCl}(705 \mathrm{mV}$ gegen SHE) bei $\mathrm{pH} 7 \mathrm{mit} 25 \mathrm{mV} / \mathrm{s}$ in $226 \mathrm{mM} \mathrm{CiP}$.

Weiterhin gelang während dieser Arbeit erstmalig die Detektion des direkten Redoxprozesses von kovalent gebundener BOD, bzw. eines ihrer Kupferzentren, an einer MWCNT-modifizierten Goldelektrode, wie in Abbildung 4.23 zu sehen.

Aus der Auswertung der Messungen, von denen eine in Abbildung 4.23 dargestellt ist, ergab sich ein formales Potential von $445 \pm 10 \mathrm{mV}$ gegen $\mathrm{Ag} / \mathrm{AgCl}$ (680 mV gegen SHE) bei pH 7 mit einer Scanrate von $25 \mathrm{mV} / \mathrm{s}$. Aufgrund des hohen Wertes kann dieses Potentials keinem der Kupferzentren klar zugeordnet werden.

Ein signifikantes Detail in den Zyklovoltammogrammen ist der sehr kleine Oxidationspeak im Gegensatz zum wesentlich deutlicher erkennbaren Reduktionspeak. Davon ausgehend, daß es sich hierbei um das T1-Kupferzentrum handelt, das reduziert und oxidiert wurde, kann die Situation wie folgt erklärt werden: Das T1-Zentrum kann Elektronen gut aufnehmen, wie seine Funktion als Elektronenakzeptor bei der Bilirubinoxidation zeigt, da es relativ weit außen im Protein liegt. T1 ist mit dem trinuklearen Cluster (T2/T3) über einen internen Elektronentransferweg (IET-Weg) gekoppelt, der 


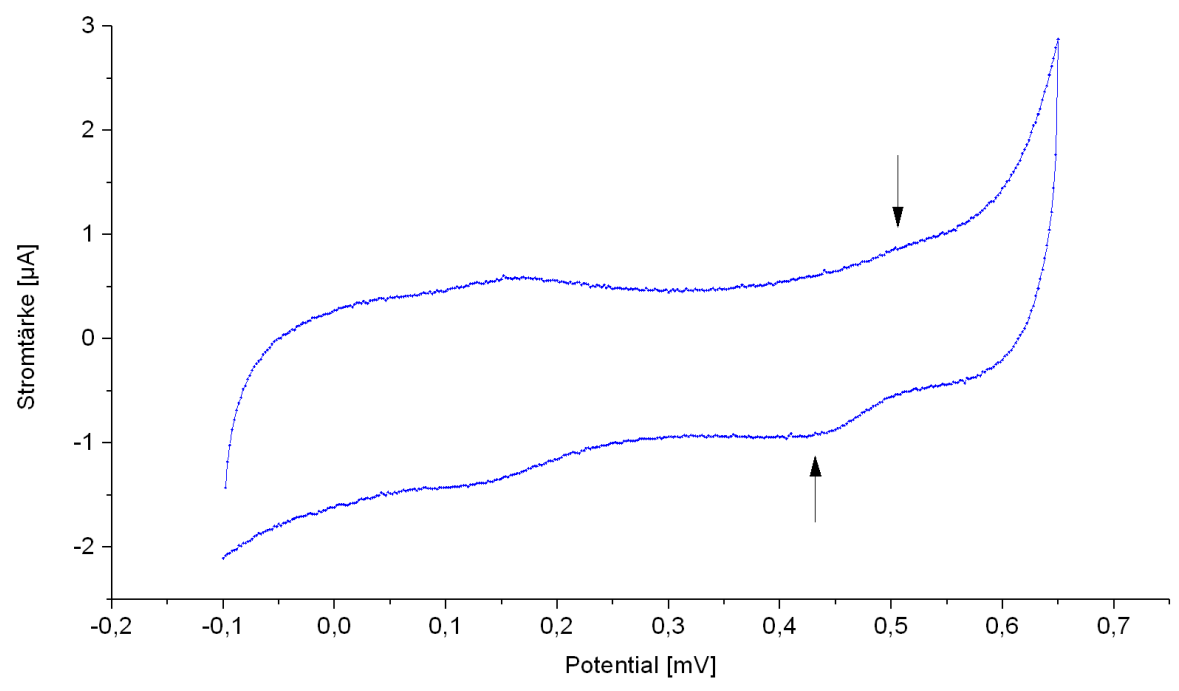

Abbildung 4.22: Direkte Redox-Umwandlung eines Kupferzentrums von BOD unter anaeroben Bedingungen, BOD mit einer Dialysemembran (MWCO $8 \mathrm{kDa}$ ) auf einer MWCNTmodifizierten Goldelektrode fixiert, $\mathrm{CV}$ in $226 \mathrm{mM} \mathrm{CiP,}$ pH 7 mit $25 \mathrm{mV} / \mathrm{s}$; Potential gegen $\mathrm{Ag} / \mathrm{AgCl}$

zu einer schnellen Weitergabe der Elektronen von T1 an T2/T3 führt. Somit ist die Oxidation von T1 durch T2/T3 wesentlich mehr begünstig als durch die Elektrode. Da unter anaeroben Bedingungen kein finaler Elektronenakzeptor $\left(\mathrm{O}_{2}\right)$ vorhanden ist, der die Elektronen am T2/T3-Cluster wieder abnimmt, kann der IET höchstens solange erfolgen, bis das Kupfer von T2/T3 vollständig reduziert ist. In vereinfachter Betrachtung würde sich nach der Anzahl der Kupferionen ein Verhältnis der Peakstromhöhe von 4:1 für Reduktion:Oxidation ergeben, da 4 Kupferionen (T1, T2, T3) reduziert werden können, aber nur 1 Kupferion (T1) wieder oxidiert würde, da der IET nur von T1 nach T2/T3 stattfindet.

Es kann jedoch nicht vollständig ausgeschlossen werden, daß der im Vergleich zum Oxidationspeak größere Reduktionspeak auch auf eine sehr kleine katalytische Restaktivität der BOD zurückzuführen ist. Das verwendete Argongas zur Verdrängung des Sauerstoffs war hochrein, kann aber immer noch Spuren von Sauerstoff enthalten $(<0,1$ ppm-mol\%, lt. Angabe des Herstellers). 

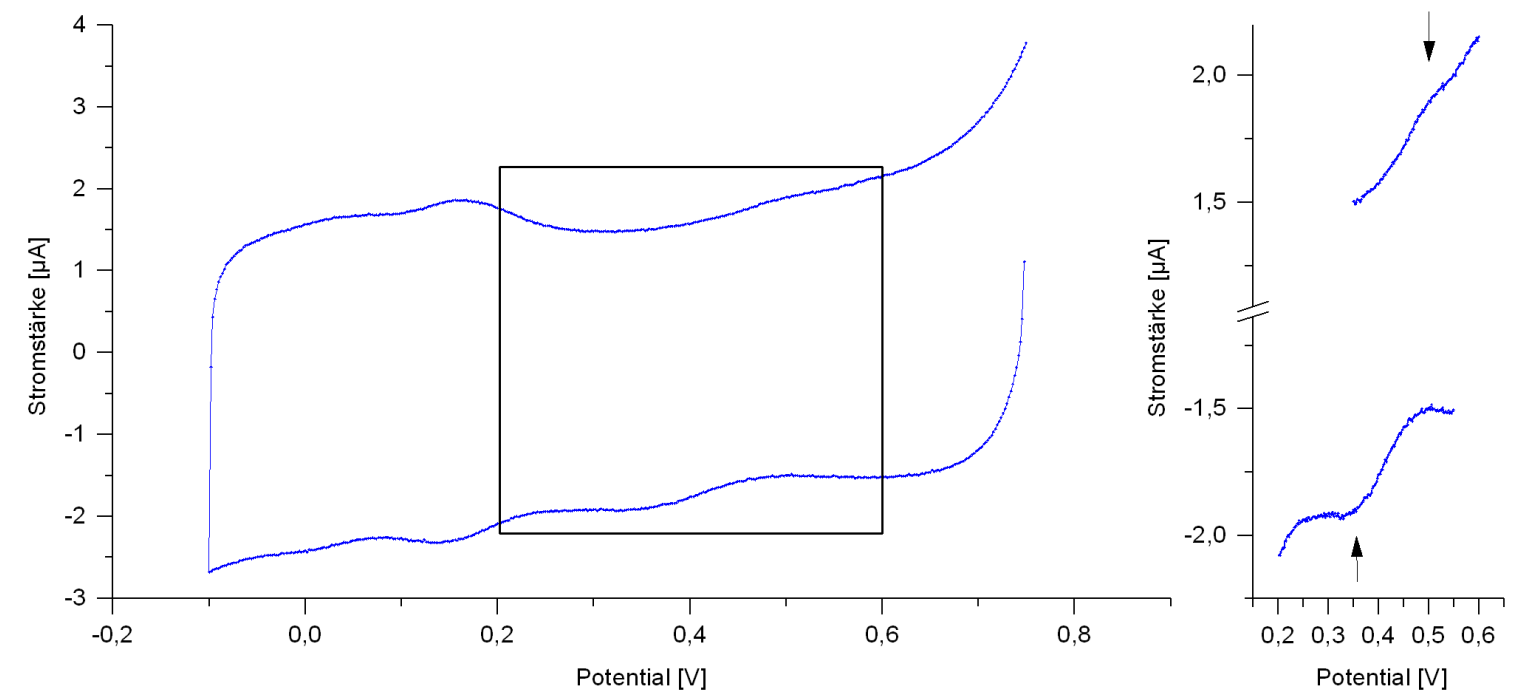

Abbildung 4.23: Direkte Redox-Umwandlung eines Kupferzentrums von kovalent gebundener BOD unter anaeroben Bedingungen, BOD kovalent gebunden an einer MWCNTmodifizierten Goldelektrode, $\mathrm{CV}$ in $100 \mathrm{mM} \mathrm{CiP,} \mathrm{pH} 7 \mathrm{mit} 25 \mathrm{mV} / \mathrm{s}$; Potential gegen $\mathrm{Ag} / \mathrm{AgCl}$

Die Frage, die sich bei den Experimenten jedoch stellt, ist: Um welches Kupferzentrum handelt es sich, das hier einer Redox-Umwandlung unterworfen wurde, bzw. das auch durch die Detektion des katalytischen Stromes beobachtet wurde? Wie im Abschnitt 2.2 schon aufgezeigt, sind in der Literatur dazu widersprüchliche Meinungen zu finden. Für das Standardpotential von T1 wurden mit Redoxtitration verschiedene Werte publiziert. Bei neueren elektrochemischen Untersuchungen emittelten Tsujimura et al. (2005) gegen 3 verschiedene Redoxmediatoren ein Standardpotential von $660 \mathrm{mV}$ (bei pH 7, gegen SHE) und Christenson et al. (2006) gegen 2 Redoxmediatoren ein Standardpotential von $670 \mathrm{mV}$ (bei pH 7, gegen SHE) für das T1-Kupferzentrum.[1] Bei voltammetrischen Messungen wurde der Start der bioelektrokatalytischen Sauerstoffreduktion durch BOD bei Potentialen von etwa $700 \mathrm{mV}$ beobachtet. Tsujimura et al. (2004) bestimmten ein Startpotential von $735 \mathrm{mV}$ (bei pH 7, gegen SHE).[17] Kamitaka et al. (2006) publizierten ein Startpotential von $695 \mathrm{mV}$ (bei pH 7, gegen SHE).[18] Die in den hier diskutierten Experimenten bestimmten Werte für das Startpotential der Sauerstoffreduktion $(720 \mathrm{mV}$, bei 
pH 7, gegen SHE) und das formale Potential (680 mV, bei pH 7, gegen SHE) entsprechen demnach in etwa den eben genannten Werten aus der Literatur.

Es gibt aber eine Reihe weiterer Argumente, die für T1 als das Kupferzentrum sprechen, das hier diskutiert wird. Bei den Experimenten von Kamitaka et al. [18] mit einer BOD-Mutante (M467Q), bei der eine Aminosäure am T1-Zentrum ausgetauscht wurde, ergab sich bei voltammetrischen Messungen eine Verschiebung des Startpotentials von $695 \mathrm{mV}$ nach $465 \mathrm{mV}$ (gegen SHE) der katalytischen Sauerstoffreduktionskurve durch die Mutation. Wie schon erwähnt, ist die Position des T1-Zentrums im Protein günstiger für einen Elektronentransfer von der Elektrode als die des T2- oder T3-Zentrums, die weiter im Inneren liegen. Die strukturellen Gegebenheiten hängen schließlich mit der natürlich Funktion von T1 als Akzeptorstelle für Elektronen von Bilirubin bei dessen Oxidation zusammen. Auch die Untersuchung der Wechselwirkung mit Bilirubin unter aeroben Bedingungen spricht zumindest teilweise für eine Elektronentransfer zum T1Zentrum in BOD. Ein weiterer Punkt ist das auffällige Verhältnis von Reduktions- und Oxidationspeakstrom, das oben schon angesprochen wurde.

In den Zyklovoltammogrammen erscheint reproduzierbar auch ein zweites Peakpaar mit einem formalen Potential von etwa $150 \mathrm{mV}$ (gegen $\mathrm{Ag} / \mathrm{AgCl}$, bei $\mathrm{pH} 7$ mit $10 \mathrm{mV} / \mathrm{s}$ ), dessen Reduktionspeak auch im Voltammogramm bei LSV erkennbar war. Es wurden Kontrollexperimente durchgeführt, die die Beschichtung der Elektrode (MWCNT, SulfoGMBS) als Ursache ausschließen. Bei der Messung von BSA, das wie BOD kovalent an eine MWCNT-modifizierte Goldelektrode gebunden wurde, trat ein Peakpaar mit einem ähnlichen formalen Potential auf (165 mV gegen $\mathrm{Ag} / \mathrm{AgCl}$, bei $\mathrm{pH} 7$ mit $25 \mathrm{mV} / \mathrm{s}$ ). Bis jetzt wird vermutet, daß es sich hierbei um Cysteinreste auf der Proteinoberfläche handelt. $\mathrm{Ob}$ dennoch diese Redoxpeaks möglicherweise einem weiteren Kupferzentrum von BOD zugeschrieben werden können, muß in weiteren Experimenten geklärt werden, bei denen das Kupfer aus BOD entfernt wird. Diese Experimente waren im Zeitrahmen dieser Arbeit leider nicht mehr durchführbar. 


\subsubsection{Zugabe von Sauerstoff in geringen Mengen}

Um zu zeigen, daß die Reduktion des beobachteten Zentrums entscheidend für den Start der bioelektrokatalytischen Sauerstoffreduktion ist, wurde BOD unter anaeroben Bedingungen voltammetrisch gemessen und in kleinen Mengen $(2 \mu \mathrm{l})$ schrittweise luftgesättigter Puffer dem Meßpuffer beigemengt.

Anhand Abbildung 4.24 ist deutlich zu erkennen, daß durch die Zugabe von luftgesättigtem Puffer eine Signalzunahme stattfand. Der katalytische Strom der Sauerstoffreduktion entstand bei etwa demselben Potential, bei dem auch der Reduktionspeakstrom unter anaeroben Bedingungen detektiert wurde. Demnach wird durch die Reduktion dieses Kupferzentrums die bioelektrokatalytische Sauerstoffreduktion angeschaltet.

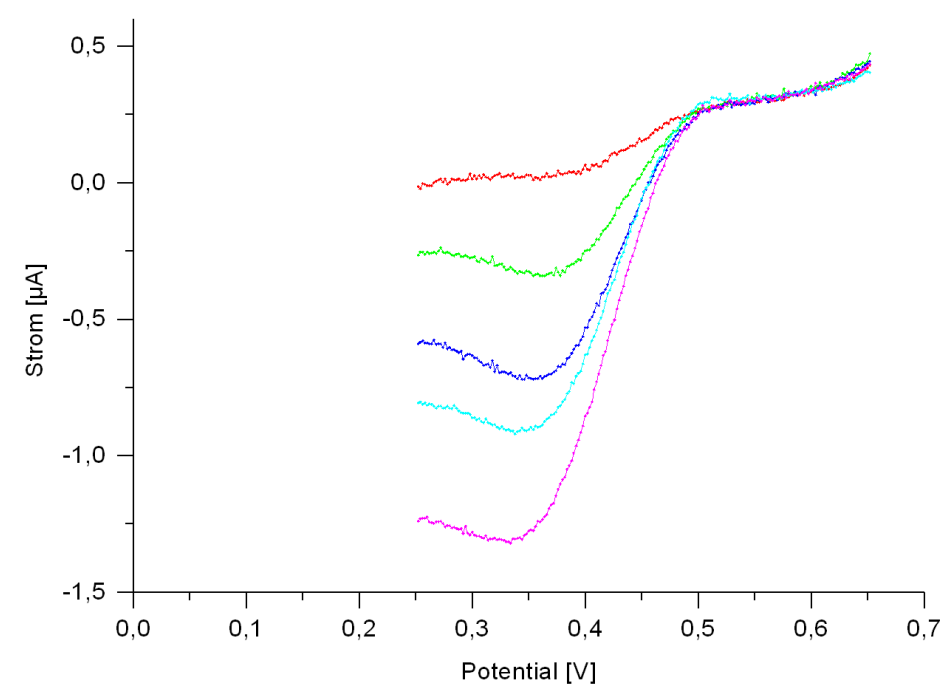

Abbildung 4.24: Zugabe von luftgesättigtem Puffer in kleinen Mengen zu anaerober Messung von BOD, BOD kovalent gebunden an einer MWCNT-modifizierten Goldelektrode, CV in $100 \mathrm{mM} \mathrm{CiP,} \mathrm{pH} 7 \mathrm{mit} 25 \mathrm{mV} / \mathrm{s}$; Ausschnitt aus CV (-) anaerob, Zugabe von (-) $2 \mu \mathrm{l},(-) 4 \mu \mathrm{l},(-) 6 \mu \mathrm{l},(-) 10 \mu \mathrm{l}$ luftgesättigtem Puffer; Potential gegen $\mathrm{Ag} / \mathrm{AgCl}$ 


\subsubsection{Wechselwirkung mit Bilirubin}

Die Wechselwirkung von BOD mit Bilirubin wurde auch unter anaeroben Bedingungen untersucht.

Der Reduktionspeakstrom sank bei hoher Bilirubinkonzentration auf nahezu Null (siehe Abb. 4.25). Dieses Experiment zeigt, daß die Redoxumwandlung des betreffenden Kupferzentrums mit Bilirubin unterdrückt werden kann. Geht man von einem möglichen Elektronentransfer zwischen T2 oder T3 und der Elektrode aus, müßte jedoch unter Anwesenheit von Bilirubin im Überschuß und anaeroben Bedingungen ein katalytischer Oxidationsstrom entstehen, da ständig Elektronen von Bilirubin auf BOD übertragen und über T2 oder T3 von der Elektrode akzeptiert würden. Ein solcher katalytischer Strom ist jedoch bei keinem Potential im CV zu verzeichnen, was einen DET zwischen Elektrode und dem T2- oder T3-Zentrum unwahrscheinlich macht. Demnach unterstützt dieses Experiment die These, daß der DET zwischen der MWCNT-modifizierten Goldelektrode und dem T1-Kupferzentrum der BOD stattfindet.

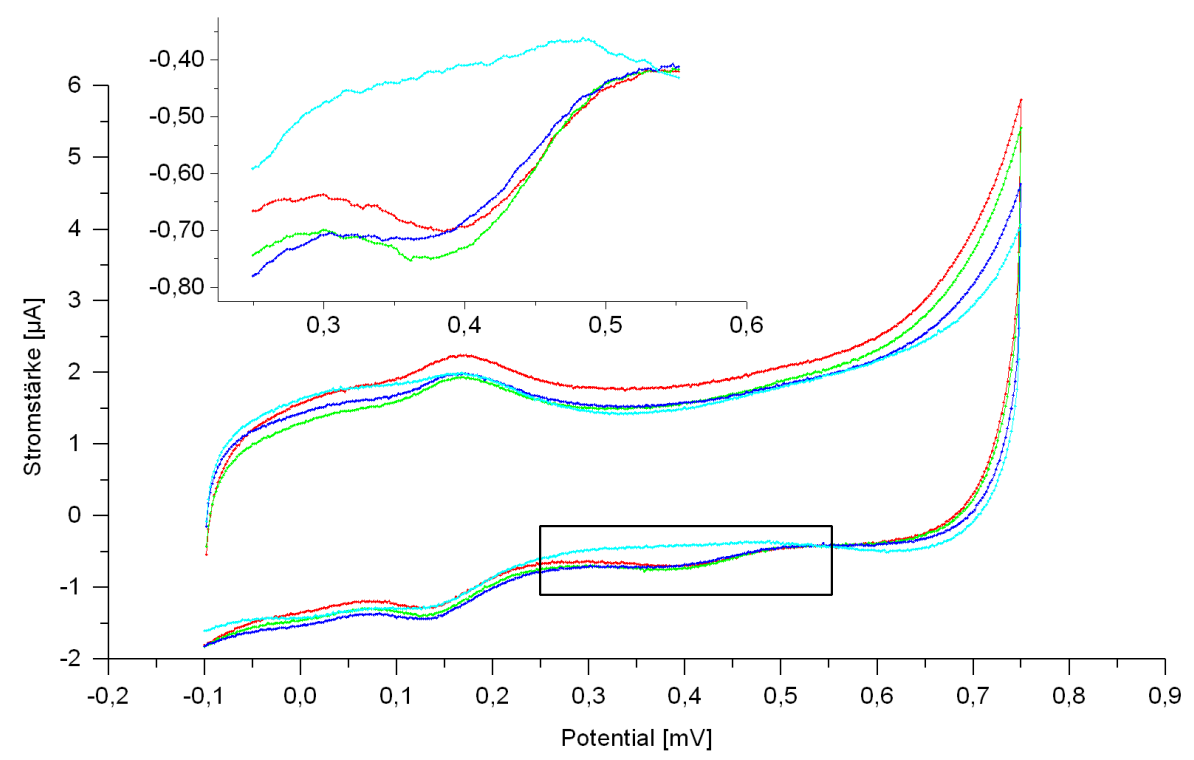

Abbildung 4.25: Wechselwirkung mit Bilirubin unter sauerstoffarmen Bedingungen, CV in $100 \mathrm{mM}$ $\mathrm{CiP}, \mathrm{pH}$ 7, BOD kovalent gebunden an einer MWCNT-modifizierten Goldelektrode; (-) ohne, (-) $10 \mathrm{mM},(-) 50 \mathrm{mM},(-) 100 \mathrm{mM}$ Bilirubin; Potential gegen $\mathrm{Ag} / \mathrm{ACl}$ 


\subsubsection{Wechselwirkung mit Inhibitoren}

Die voltammetrischen Messungen (LSV) unter Wechselwirkung mit Inhibitoren wurden auch unter Sauerstoffausschluß durchgeführt. In Abbildung 4.26 sind die anaeroben Messungen bei Zugabe von Natriumfluorid dargestellt.

In den Voltammogrammen ist deutlich eine Verschiebung des Reduktionspeakpotentials zu negativeren Werten zu erkennen. Die Auftragung des Peakpotentials gegenüber der NaF-Konzentration legt eine lineare Abhängigkeit nahe (siehe Abb. 4.26).

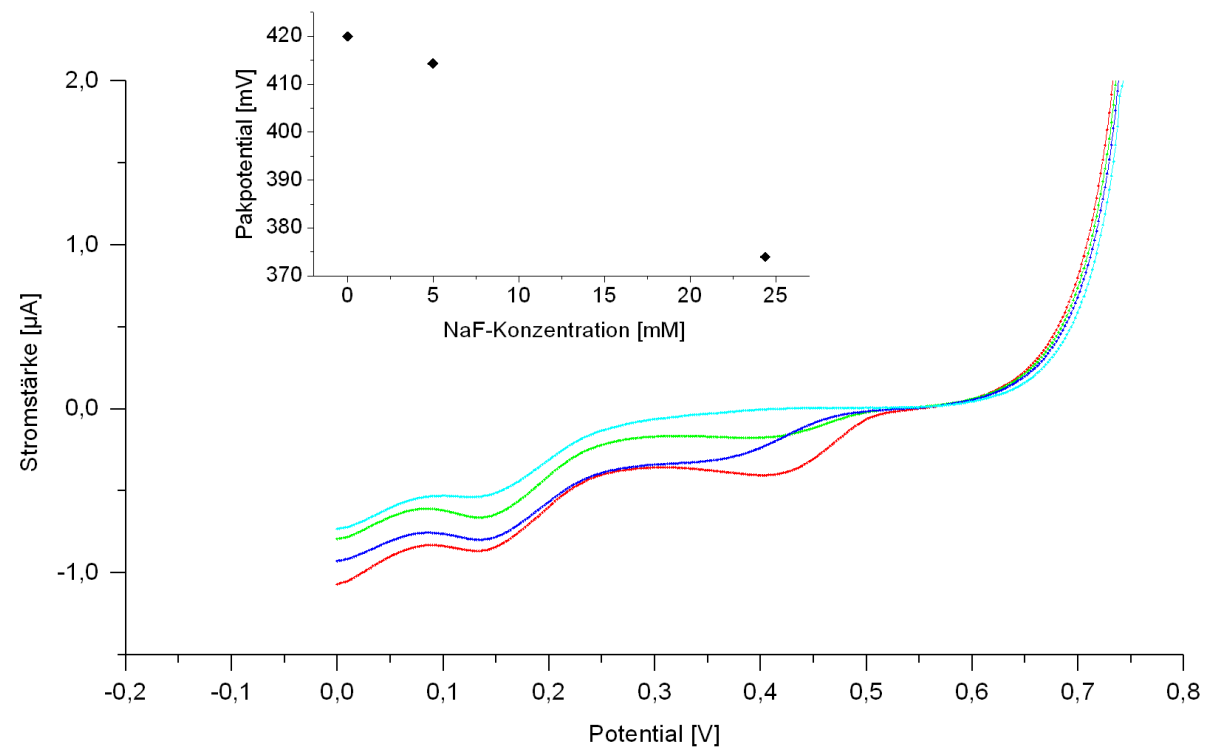

Abbildung 4.26: Wechselwirkung mit NaF unter anaeroben Bedingungen, LSV in $100 \mathrm{mM} \mathrm{CiP,} \mathrm{pH} 7$, BOD kovalent gebunden an einer MWCNT-modifizierten Goldelektrode; (-) ohne, (-) $5 \mathrm{mM},(-) 24,4 \mathrm{mM},(-) 47,6 \mathrm{mM} \mathrm{NaF}$; Potentiale gegen $\mathrm{Ag} / \mathrm{AgCl}$

Bei einer Inhibierung könnte man annehmen, daß der Reduktionspeakstrom mit zunehmender Natriumfluoridkonzentration stetig abnimmt. In Abbildung 4.26 ist jedoch eine deutliche Signalzunahme bei $24,4 \mathrm{mM}$ gegenüber $5 \mathrm{mM} \mathrm{NaF}$ zu verzeichnen.

Möglicherweise wurde bei dieser Messung Sauerstoff in den Meßpuffer eingetragen, bzw. nicht vollständig wieder entfernt, was zu einem kleinen katalytischen Strom führte. Die Komplexierung durch die Fluoridionen kann jedoch auch zu einer Verbesserung des Redoxprozesses führen. Da es sich um Einzelmessungen handelte, kann dazu keine 


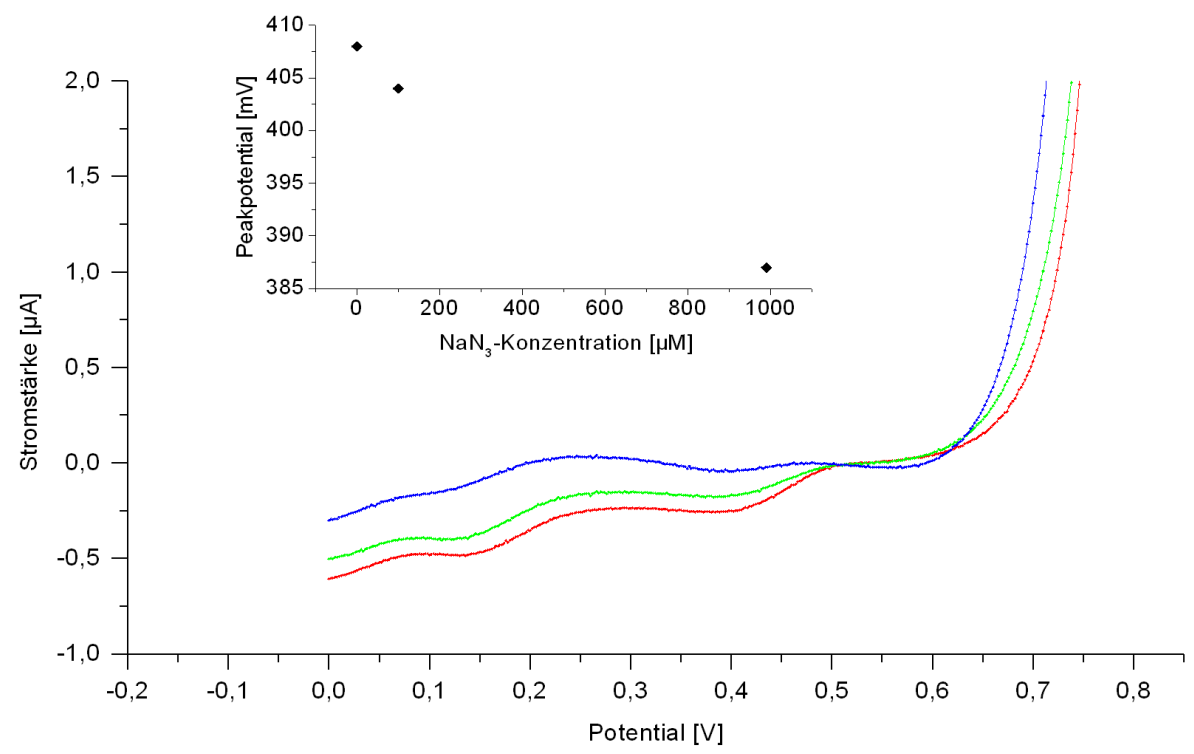

Abbildung 4.27: Wechselwirkung mit $\mathrm{NaN}_{3}$ unter anaeroben Bedingungen, LSV in $100 \mathrm{mM} \mathrm{CiP,} \mathrm{pH}$ 7, BOD kovalent gebunden an einer MWCNT-modifizierten Goldelektrode; (-) ohne, (-) $100 \mathrm{mM},(-) 1000 \mu \mathrm{M} \mathrm{NaN}_{3}$; Potentiale gegen $\mathrm{Ag} / \mathrm{AgCl}$

abschließende Erklärung gegeben werden. Bei 47,6 mM NaF wurde der Reduktionspeakstrom vollständig unterdrückt.

Die Beseitigung des Reduktionspeaks bei hoher Fluoridionenkonzentration spricht für eine starke Komplexierung aller $\mathrm{Cu}$-Ionen seitens $\mathrm{NaF}$.

Ein markantes Detail ist das konstante Auftreten des 2. Reduktionspeaks trotz anwesender Fluoridionen. Das unterstützt die aufgrund des BSA-Experimentes getroffene Vermutung, daß es sich hierbei nicht um ein weiteres Kupferzentrum handelt.

Die beobachtete Verschiebung des Reduktionspeakpotentials kann auf die Komplexierung durch die Fluoridionen zurückgeführt werden.

Das elektrochemische Verhalten von BOD unter Wechselwirkung mit Natriumazid und Sauerstoffausschluß entspricht wie zu erwarten dem unter Wechselwirkung mit Natriumfluorid. Die Abbildung 4.27 zeigt mit zunehmender $\mathrm{NaN}_{3}$-Konzentration wieder die zunehmende Unterdrückung des Reduktionpeakstromes und die Verschiebung des Reduktionspeakpotentials zu negativeren Werten. Die Bewertung dieser Ergebnisse erfolgt in gleicher Weise wie für Natriumfluorid. 
Da die Azid- und Fluoridionen wahrscheinlich die Kupferionen in allen Zentren komplexieren können [3, 28], kann aus diesen Experimenten kein weiterer Hinweis auf das detektierte Kupferzentrum gefunden werden. 


\section{Zusammenfassung}

In der vorliegenden Arbeit wurden Goldelektroden mit mehrwandigen Kohlenstoffnanoröhren modifiziert und darauf Bilirubinoxidase kovalent fixiert. An diesem Elektrodensystem wurden unter Variation verschiedener Parameter elektrochemische Untersuchungen zur Kommunikation zwischen Protein und Elektrode durchgeführt. Zu diesen Parametern gehörten präparative Faktoren wie Ultraschallbehandlung der MWCNTs, Auftragungsmenge der MWCNTs und BOD-Konzentration während der kovalenten Immobilisierung, Meßbedingungen wie pH-Wert und Ionenstärke des Meßpuffers, die Lagerzeit der Elektrode und außerdem der Einfluß von Substrat und Inhibitoren unter aeroben und anaeroben Bedingungen. Zudem konnte erstmalig die elektrochemische Umwandlung von kovalent fixierter BOD an MWCNT-modifizierten Goldelektroden direkt voltammetrisch nachgewiesen werden.

BOD ist eine "Blaue" Multikupferoxidase mit 3 Kupferzentren (T1, T2 und T3), die 4 Kupferionen enthalten. Dieses Enzym katalysiert die Oxidation von Bilirubin zu Biliverdin unter Verwendung der Elektronen für die Reduktion von Sauerstoff zu Wasser. Die MWCNTs waren thiolmodifiziert und konnten daher sehr stabil auf der Goldoberfläche gebunden werden. BOD wurde über den crosslinker Sulfo-GMBS an den Thiolgruppen der MWCNTS kovlent fixiert.

Unter aeroben Bedingungen konnte ein DET von der Elektrode zur BOD durch die bioelektrokatalytische Reduktion von Sauerstoff zu Wasser detektiert werden. Experimente mit Inhibitoren zeigten, daß die katalytische Aktivität eindeutig auf das Enzym zurückzuführen ist. Das Startpotential der Elektrodenreaktion unter aeroben Bedingungen wurde mit etwa $720 \pm 10 \mathrm{mV}$ gegen SHE ermittelt. Das entspricht in etwa den Werten, die für voltammetrische Messungen der Sauerstoffreduktion durch BOD in der Literatur beschrieben wurden.[17, 18] Mit dem hier vorgestellten Elektrodensystem sind Stromdichten im Bereich von etwa $500 \mu \mathrm{A} / \mathrm{cm}^{2}$ möglich, was deutlich höher liegt als die aus der Literatur bekannten Werte.[17, 18] 
Das Elektrodensystem wurde zunächst hinsichtlich des Einflusses verschiedener präparativer Parameter untersucht. Durch die Ultraschallbehandlung der MWCNTs vor der Beschichtung konnte eine deutliche Erhöhung des katalytischen Stromes für BOD in Lösung und des Peakstromes für ein Redoxsystem (KHCF) erzielt werden. Mit Erhöhung der Auftragungsmenge der MWCNTs bis etwa $10 \mu \mathrm{g}$ konnte ebenfalls eine Verbesserung der voltammetrischen Meßssignale für BOD in Lösung und KHCF erzielt werden. Bei diesem Experiment zeigte sich auch, daß ohne die MWCNT-Schicht auf der Goldelektrode kein katalytischer Strom durch die Bilirubinoxidase detektierbar war. Die MWCNTs auf der Goldelektrode waren essentiell zum Erhalt der katalytischen Aktivität der BOD. Die Variation der BOD-Konzentration während der kovalenten Immobilisierung ergab eine optimale Konzentration von etwa $10 \mu \mathrm{M}$.

Weiterhin wurde der Einfluß verschiedener Meßbedingungen untersucht. Die bioelektrokatalytische Reduktion von Sauerstoff wies eine pH-Abhängigkeit auf. Die Halbstufenpotentiale der voltammetrischen Meßkurven verschoben sich um etwa $-29 \mathrm{mV} / \mathrm{pH}$. Diese Abhängigkeit entspricht der Nernst'schen Gleichung und beschreibt einen Prozeß, bei dem 2 Elektronen übertragen werden. Die katalytische Aktivität der kovalent gebundenen BOD wies ein Maximum bei pH 6-7 auf. Das Startpotential der bioelektrokatalytischen Sauerstoffreduktion verschob sich mit zunehmender Ionenstärke im Meßpuffer zu immer positiveren Werten. Ab etwa $10 \mathrm{mM}$ Pufferkonzentration blieb die Höhe des voltammetrischen Meßsignals von der Ionenstärke weitgehend unbeeinflußt. Bei der Untersuchung der Lagerstabilität erwies sich die kovalent gebundene BOD im Vergleich zu vielen anderen Proteinelektroden als sehr stabil. Nach fast 2 Monaten Lagerdauer in $100 \mathrm{mM}$ CiP-Puffer bei $5^{\circ} \mathrm{C}$ konnte immer noch eine katalytische Aktivität detektiert werden. Damit scheint dieses Elektrodensystem gut geeignet zu sein zur Weiterentwicklung für biomedizinische Anwendungen in physiologischen Medien.

Bei voltammetrischen Messungen in Lösungen mit verschiedenen Sauerstoffkonzentrationen konnte gezeigt werden, daß sich das verwendete Elektrodensystem auch als Biosensor zur Detektion der Sauerstoffkonzentration in wäßrigen Medien eignet. Der katalytische Strom wies dabei eine lineare Abhängigkeit im gesamten Meßbereich auf, der sich von sauerstoffarmem bis luftgesättigten Puffer erstreckte. 
Unter anaeroben Bedingungen wurde ein Kupferzentrum der Bilirubinoxidase einer direkten Redoxumwandlung unterworfen. Der Nachweis dieses Redoxprozesses gelang erstmalig mit kovalent fixierter Bilirubinoxidase. Bei pH 7 in $100 \mathrm{mM}$ CiP-Puffer mit $25 \mathrm{mV} / \mathrm{s}$ wurde ein formales Potential von etwa $680 \pm 10 \mathrm{mV}$ gegen SHE bestimmt. Dieses Redoxpotential entspricht den Werten neuerer elektrochemischer Untersuchungen von Tsujimura et al. [17], Christenson et al. [1], Kamitaka et al. [18] und Weigel et al. [24. Durch Zugabe von Sauerstoff konnte gezeigt werden, daß dieses Kupferzentrum entscheidend für den Start der bioelektrokatalytischen Sauerstoffreduktion ist. Um Hinweise auf die Art des Kupferzentrums zu finden, das beim DET die Elektronen von der Elektrode akzeptiert, wurden außerdem voltammetrische Messungen unter Wechselwirkung mit Bilirubin und den Inhibitoren Natriumfluorid und Natriumazid durchgeführt. Diese erfolgten sowohl unter aeroben, als auch anaeroben Bedingungen. Dem beobachteten Verhalten nach deuten diese Experimente auf das T1-Kupferzentrum. Davon ausgehend, daß sich die in den letzten Jahren publizierten Standardpotentiale für das T1-Zentrum von BOD [1] als richtig erweisen, stützen auch die in der vorliegenden Arbeit bestimmten Potentiale die These des direkten Elektronentransfers auf das T1-Kupferzentrum der Bilirubinoxidase.

Vor dem Hintergrund der aktuellen Klimadiskussion bedarf es sicherlich noch einiger Bemühungen, effiziente alternative Energiequellen zu erschließen. Vor allem bei der Versorgung von Kleingeräten wie Mobiltelephone oder auch Herzschrittmacher sind Entwicklungen von Bioenergiezellen vielversprechend. Bilirubinoxidase in Verbindung mit MWCNTs ist möglicherweise einer der vielversprechendsten Kandidaten, um in das Kathodensystem solcher Bioenergiezellen integriert zu werden. Das weitere Ziel der Forschung diesbezüglich ist es vor allem, Elektrodensysteme zu entwickeln, die sich durch eine höhere Energieausbeute und Stabilität auszeichnen.

Auch bei der Erforschung der Bilirubinoxidase selbst sind noch Fragen offen, die zukünftig weiter untersucht werden müssen. Bis jetzt ist noch nicht endgültig geklärt, welche Prozessen im Einzelnen vor allem beim direkten Elektronentransfer zwischen dem Enzym und der Elektrode ablaufen. Wenn diese Mechanismen besser bekannt sind, kann die BOD vielleicht auch effektiver bei elektrochemischen Anwendungen eingesetzt werden. 


\section{Literaturverzeichnis}

[1] A. Christenson, S. Shleev, N. Mano, A. Heller und L. Gorton. Redox potentials of the blue copper sites of bilirubin oxidases. Biochimica et Biophysica Acta, 1757:1634-1641, 2006.

[2] R. A. Bullen, T. C. Arnot, J. B. Lakeman und F. C. Walsh. Biofuel cells and their development. Biosensors and Bioelectronics, 21:2015-2045, 2006.

[3] S. Shleev, J. Tkac, A. Christenson, T. Ruzgas, A. I. Yaropolov, J. W. Whittaker und L. Gorton. Direct electron transfer between copper-containing proteins and electrodes. Biosensors and Bioelectronics, 20:2517-2554, 2005. und darin zitierte Literatur.

[4] E. Katz und I. Willner. Biomolecule-functionalized carbon nanotubes: Applications in nanobioelectronics. ChemPhysChem, 5:1084-1104, 2004.

[5] R. Dagani. Nanotube strands are centimeters long. Chemical \& Engineering News, 80(18):11, 2002.

[6] C. N. R. Rao und A. Govindaraj. Nanotubes and Nanowires. RSC Nanosciences \& Nanotechnology. RSC Publishing, Cambridge, UK.

[7] J.-C. Charlier. Defects in carbon nanotubes. Accounts of Chemical Research, 35:1063-1069, 2002.

[8] Kohlenstoffnanoröhre. URL, de.wikipedia.org/wiki/Kohlenstoffnanoröhre, Juli 2007.

[9] J. J. Gooding. Nanostructuring electrodes with carbon nanotubes: A review on electrochemistry and applications for sensing. Electrochimica Acta, 50:3049-3060, 2005. und darin zitierte Literatur.

[10] C. E. Banks und R. G. Compton. New electrodes for old: from carbon nanotubes to edge plane pyrolytic graphite. Analyst, 131:15-21, 2006.

[11] C. Yang, X. Hu, D. Wang, C. Dai, L. Zhang, H. Jin und S. Agathopoulos. Ultrasonically treated multi-walled carbon nanotubes (MWCNTs) as PtRu catalyst supports for methanol electrooxidation. Journal of Power Sources, 160:187-193, 2006 . 
[12] S. Koikeda, K. Ando, H. Kaij, T. Inoue, S. Murao, K. Takeuchi und T. Samejima. Molecular cloning of the gene for bilirubin oxidase from Myrothecium verrucaria and its expression in yeast. The Journal of Biological Chemistry, 268(25):18801-18809, 1993.

[13] A. Shimizu, J.-H. Kwon, T. Sasaki, T. Satoh, N. Sakurai, T. Sakurai, S. Yamaguchi und T. Samejima. Myrothecium verrucaria bilirubin oxidase and its mutants for potential copper ligands. Biochemistry, 38:3034-3042, 1999.

[14] K. Kataoka, R. Kitagawa, M. Inoue, D. Naruse, T. Sakurai und H.-w. Huang. Point mutations at the type I Cu ligands, Cys457 and Met467, and at the putative proton donor, Asp105, in Myrothecium verrucaria bilirubin oxidase and reactions with dioxygen. Biochemistry, 44:7004-7012, 2005.

[15] A. Shimizu, T. Samejima, S. Hirota, S. Yamaguchi, N. Sakurai und T. Sakurai. Type III Cu mutants of Myrothecium verrucaria bilirubin oxidase. The Journal of Biochemistry, 133(6):767-772, 2003.

[16] A. Shimizu, T. Sasaki, J. H. Kwon, A. Odaka, T. Satoh, N. Sakurai, T. Sakurai, S. Yamaguchi und T. Samejima. Site-directed mutagenesis of a possible type 1 copper ligand of bilirubin oxidase; a met467gln mutant shows stellacyanin-like properties. The Journal of Biochemistry, 125:662-668, 1999.

[17] S. Tsujimura, T. Nakagawa, K. Kano und T. Ikeda. Kinetic study of direct bioelectrocatalysis of dioxygen reduction with bilirubin oxidase at carbon electrodes. Electrochemistry, 72(6):437-439, 2004.

[18] Y. Kamitaka, S. Tsujimura, K. Kataoka, T. Sakurai, T. Ikeda und K. Kano. Effects of axial ligand mutation of the type I copper site in bilirubin oxidase on direct electron transfer-type bioelectrocatalytic reduction of dioxygen. Journal of Electroanalytical Chemistry, 2006. doi:10.1016/j.jelechem.2006.10.035.

[19] N. Mano, H.-H. Kim, Y. Zhang und A. Heller. An oxygen cathode operating in a physiological solution. Journal of the American Chemical Society, 124:6480-6486, 2002.

[20] N. Mano und A. Heller. A miniature membraneless biofuel cell operating at $0.36 \mathrm{~V}$ under physiological conditions. Journal of The Electrochemical Society, 150(8):A1138-A1138, 2003.

[21] H.-H. Kim, N. Mano, Y. Zhang und A. Heller. A miniature membrane-less biofuel cell operating under physiological conditions at $0.5 \mathrm{~V}$. Journal of The Electrochemical Society, 150(2):A209-A213, 2003.

[22] J. Lim, P. Malati, F. Bonet und B. Dunn. Nanostructured sol-gel electrodes for biofuel cells. Journal of The Electrochemical Society, 154(2):A140-A145, 2007. 
[23] W. Zheng, Q. Li, L. Su, Y. Yan, J. Zhang und L. Mao. Direct electrochemistry of multi-copper oxidases at carbon nanotubes noncovalently functionalized with cellulose derivatives. Electroanalysis, 18(6):587-594, 2006.

[24] M. Ch. Weigel, E. Tritscher und F. Lisdat. Direct electrochemical conversion of bilirubin oxidase at carbon nanotube-modified glassy carbon electrodes. Electrochemistry Communications, 9(4):689-693, 2007.

[25] R. Dronov, D. G. Kurth, F. W. Scheller und F. Lisdat. Direct and cytochrom $c$ mediated electrochemistry of bilirubin oxidase on gold. Electroanalysis, 19(15):16421646, 2007.

[26] R. M. C. Dawson, D. C. Elliot, W. H. Elliot und K. M. Jones. pH and buffers, pages 475-508. Data for biochemical research. Clarendon Press, New York, 1974.

[27] K. Kataoka, K. Tanaka, Y. Sakai und T. Sakurai. High-level expression of Myrothecium verrucaria bilirubin oxidase in Pichia pastoris, and its facile purification and characterization. Protein Expression and Purification, 41:77-83, 2005.

[28] N. J. Blackburn, M. Concannon, S. K. Shahiyan, F. E. Mabbs und D. Collison. Active site of dopamine \& hydroxylase. comparison of enzyme derivatives containing four and eight copper atoms per tetramer using potentiometry and EPR spectroscopy. Biochemistry, 27:6001-6008, 1988. 


\section{Selbständigkeitserklärung}

Hiermit erkläre ich, daß ich die vorliegende Arbeit selbständig angefertigt und keine anderen als die angegebenen Quellen und Hilfsmittel benutzt habe.

Wildau, den 13. August 2007

Kirsten Schubert 